\title{
Adverbial -s as last resort
}

\section{$n$ and $a$ get their support}

\section{Norbert Corver ${ }^{1}$}

Received: 2 August 2019 / Accepted: 22 September 2021 / Published online: 25 October 2021

(c) The Author(s) 2021

\begin{abstract}
This article examines the grammatical behavior of Dutch adverbs featuring so-called adverbial $-s$. This will be done on the basis of three questions: Firstly, what is the grammatical nature of adverbial $-s$ ? Secondly, in which structural configurations does it appear? Thirdly, what does adverbial $-s$ tell us about the existence of adverbs as a separate part of speech? The article provides the following three answers to these questions: Firstly, adverbial $-s$ is an affixal manifestation of the categorizing heads $n$ and $a$ (so-called -s-Support). Secondly, $n$ and $a$ externalize as $-s$ when the raised root that forms an amalgam with the categorizing head is silent or a bound root. Thirdly, "adverbs" featuring adverbial $-s$ are nominal, adjectival or adpositional expressions with an articulated syntactic structure. Some of these syntactic structures correspond to the so-called construct state. In short, linguistic expressions featuring adverbial $-s$ do not support the idea that adverbs form a separate part of speech.
\end{abstract}

Keywords Adverb $\cdot \mathrm{n} \cdot \mathrm{a} \cdot-\mathrm{s}-$ Support $\cdot$ Last resort $\cdot$ Construct state $\cdot$ Dutch

\section{Introduction}

I invite the reader to read the following short story written in Dutch:

a. Er was eens een kat die 's ochtends soms ineens there was once a cat which in-the-morning sometimes at-once opstond en zachtjes het huis uit sloop. up-stood and quiet-DIM-s the house out sneaked

'Once upon a time there was a cat which, sometimes, suddenly got up in the morning and silently slipped out of the house.'

$\triangle$ N. Corver

n.f.m.corver@uu.nl

1 Utrecht Institute of Linguistics-OTS, Utrecht University, Trans 10, 3512 JK Utrecht,

The Netherlands 
b. Buitenshuis ving zij telkens ergens minstens drie muizen, outdoors caught she every-time somewhere at-least three mice

die ze binnenskamers oppeuzelde.

which she indoors up-ate

'Every time she caught at some place at least three mice, which she ate indoors.'

c. De muizen zaten vaak doodsbang ondergonds in hun holletjes.

the mice sat often deadly-afraid underground in their holes

'The mice often hid under the ground in their little holes while being terrified.'

d. Eén muis, Jerry, was ietsjes minder bang. Hij gedroeg zich one mouse Jerry was somewhat less afraid he behaved REFL

anders.

differently

'One mouse, called Jerry, was somewhat less afraid. He behaved differently.'

Traditionally, the italicized elements in (1) are characterized as adverbs. A conspicuous property that these Dutch adverbs have in common is their ending in $-s$. It is therefore not surprising that, in traditional grammar, this bound morphemic element is called 'adverbial $-s$ ' (Royen 1947-1954). Identifying $-s$ as a marker signalling the part of speech 'adverb' suggests that traditional grammarians took these elements to have a composite structure. For example, the temporal adverb soms 'sometimes' in (1a) has the composite structure som $+-s$.

The aim of this article is to further our understanding of this class of adverbs which, to my knowledge, has so far been largely ignored in the morphosyntactic study of Dutch (and other Germanic languages). ${ }^{1}$ This will be done by addressing three questions: Firstly, what is the grammatical nature of adverbial $-s$ ? Secondly, what is the distribution of adverbial $-s$, that is, in which structural environments is it attested? Thirdly and most importantly from a broader theoretical perspective, what does adverbial $-s$ tell us about the existence of adverbs as a separate syntactic category; that is, do adverbs constitute a separate syntactic category (i.e., a lexical category) within the parts of speech (i.e., besides $\mathrm{N}, \mathrm{V}, \mathrm{A}, \mathrm{P}$ ) or can they be reduced to other syntactic categories?

Before providing some initial answers to these questions, I think it is useful to point out that the question about the categorial status of adverbs has been on the generative-linguistic research agenda for a while. The tendency seems to be to place so-called adverbs in one of the other lexical classes. ${ }^{2}$ For example, the adverb fast, as in John drove fast, can be related to adjectives, the temporal adverb yesterday, as

\footnotetext{
${ }^{1}$ I focus on the grammar of adverbial $-s$ in Dutch, leaving a cross-Germanic study for future research. Some illustrations of adverbial $-s$ in other Germanic languages are the following: sometimes, upwards (English), damals 'at the time,' übrigens 'by the way' (German), fierders 'for the rest,' daliks 'immediately' (Frisian).

${ }^{2}$ In Chomsky (1970), the major syntactic categories are defined in terms of the categorial features $[+/-\mathrm{N}]$ and $[+/-\mathrm{V}]$. Specifically: $[+\mathrm{N},-\mathrm{V}]=$ noun, $[-\mathrm{N},+\mathrm{V}]=$ verb, $[+\mathrm{N},+\mathrm{V}]=$ adjective, and $[-\mathrm{N},-\mathrm{V}]=$ adposition. According to this classification, adverbs do not constitute a separate lexical category; see also Alexiadou (2013).
} 
in John cried yesterday, to nouns, and the adverb downstairs, as in John went downstairs, to adpositions (Bowers 1975; Emonds 1976, 1985; Larson 1985; McCawley 1988; Jackendoff 1972). The reduction of adverbs to other syntactic categories is motivated by their (morpho-)syntactic behavior. For example, fast can be modified by degree words that typically combine with adjectives, as in very fast and how fast; the adverb yesterday can be followed by 's and act as a left branch constituent within a noun phrase, just like the nominal possessor John's. Compare, for example, yesterday's party and John's party. The fact that John's and yesterday's cannot co-occur within a single noun phrase suggests that they compete for the same position: *John's yesterday's party. Finally, the postnominal placement of downstairs in the restaurant right downstairs (is very comfortable), and its modifiability by right, corresponds to the distributional behavior and modifiability of PPs, as in the restaurant (right) down the road (is very comfortable).

The question about the categorial nature of adverbs includes the question about their syntactic compositionality; that is, to what extent do adverbs consist of smaller components? There is consensus that English -ly-adverbs such as carefully, as in John opened the door carefully, fall apart in two components: careful and -ly. It is generally assumed that the first component is an adjective. There is less agreement, though, on the grammatical nature of the bound morpheme -ly. It has been analyzed, among others, as an inflectional suffix on the adjective (Emonds 1985:201), as the lexicalization of a Relator-head that mediates in a subject-predicate-that is, $\mathrm{VP}_{\text {subject }}$

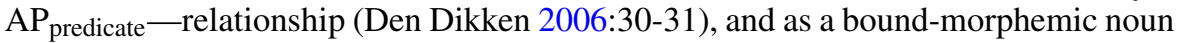
that is modified by an attributive adjective (Déchaine and Tremblay 1996; Baker 2003). ${ }^{3}$

In recent years, the perspective on lexical categories has changed radically. An approach to categories has been developed, which starts from the assumption that lexical categories (also called content words) as such do not exist as primitive elements. Rather they are roots, unspecified as to category. Their categorial status as nominal, verbal et cetera results from merger with a categorizing head (Marantz 1997; Embick and Marantz 2008). ${ }^{4}$ For example, the root kiss becomes a noun by merging with the nominalizer $n$, as in $n+\sqrt{ } k i s s$, and it becomes a verb by merging with the verbalizer $v$, as in $v+\sqrt{ }$ kiss..$^{5}$ An important consequence of this analysis is that lexical categories are syntactic objects with a composite structure.

Having provided some background for the research carried out in this article, let me return to the three earlier questions related to the grammar of Dutch adverbial $-s$. I will provide the following answers to these questions: Firstly, adverbial $-s$ is an affixal manifestation of the categorizing heads $n$ and $a$. Its appearance (-s-Support) will be analyzed as a last resort phenomenon. Secondly, the appearance of adverbial

\footnotetext{
${ }^{3}$ For further discussion of the composite structure of adverbs, see Alexiadou (2013), Delfitto and Fiorin (2017).

${ }^{4}$ See also Borer (2005) for the idea that the categories 'noun,' 'verb' et cetera are configurationally defined syntactic objects. She does not adopt categorizing heads such as $n$ and $v$ but proposes that roots become nouns or verbs by merging with functional categories such as $\mathrm{D}$ or $\mathrm{T}$, respectively.

${ }^{5}$ In the linguistics literature, roots are generally represented in upper-case letters (e.g., $\left.n+\sqrt{ } K I S S\right)$. In this article, I will simply represent them by means of lower-case letters (e.g., $n+\sqrt{ } k i s s)$ in order to distinguish them from silent (i.e., unpronounced) roots, which, in the spirit of Kayne (2003), will be represented by upper-case letters.
} 
$-s$ depends on the nature of the amalgam that results from raising of the root to $n$ or $a$. Thirdly, adverbs ending in $-s$ are syntactic objects with an internal articulated structure. Specifically, they are nominal, adjectival or adpositional syntactic objects. Thus, there is no reason for treating these $-s$-bearing expressions as belonging to a separate class of speech, namely, the class of adverbs.

The paper is organized as follows: Sect. 2 introduces the phenomenon of adverbial $-s$ by way of describing some of its distributional and morphosyntactic properties. A central claim will be that expressions featuring adverbial $-s$ have an inner syntactic structure. In Sect. 3, it is proposed that adverbial $-s$ is a last resort manifestation of the categorial heads $n$ and $a$. In Sect. 4, these two major claims - the inner structure of $-s$-bearing adverbs and the last resort nature of $-s-$ will be substantiated by means of three case studies. Each case study introduces a structural configuration in which $-s$ appears as a last resort phenomenon: Sect. 4.1 examines the pattern zachtje-s (slow-DIM(INUTIVE)-s, 'slowly'), Sect. 4.2 the pattern namens (name-en-s, 'on behalf of'), and Sect. 4.3 the pattern ondergronds (under-ground-s, 'underground, subterranean'). Section 5 broadens the empirical scope by providing case studies on temporal adverbs (5.1), measure adverbs (5.2), and degree adverbs (5.3). Section 6 extends the discussion of adverbial $-s$ to the adjectival domain. Section 7 is the conclusion. It briefly addresses the question as to what the present study on Dutch adverbial $-s$ implies for the broader (i.e., cross-linguistic) study of so-called adverbs.

\section{Some starting observations: Distribution and structure of adverbs with -s}

This section introduces the phenomenon of adverbial $-s$ by way of describing some of its distributional and morphosyntactic properties. First of all, it should be noted that adverbial $-s$ is attested on adverbs with different modifying (i.e., adverbial) roles. The short story in (1), for example, displays various adverbial uses, such as: Manner (zachtjes 'quietly,' anders 'differently'), Place (buitenshuis 'outdoors,' ergens 'somewhere,' binnenskamers 'indoors,', ondergronds 'undergrounds'), Time (eens 'once,' 's ochtends 'in the morning,' soms 'sometimes,' ineens 'at once,' telkens 'every time'), Degree (doods 'deadly, minstens 'at least'), and Measure (ietsjes 'somewhat/a little').

Secondly, adverbial $-s$ is attested on modifiers embedded within different types of phrasal constituents:

a. De [AP lichtjes gewonde] man verliet [pP eventjes na vier uur] the light-DIM-s wounded man left little-DIM-s after four hour zijn huis.

his house

'The lightly wounded man left his house a little after four o'clock.'

b. [NP Die kritiek zo eventjes] werd [vP kalmpjes weggewuifd door that criticism so just-DIM-s was calm-DIM-s aside-waved by de raad].

the board

'That criticism a few minutes ago was calmly waved aside by the board.' 
Thirdly, adverbial $-s$ is also attested in adpositional contexts. Specifically, $-s$ shows up on an element that appears to be a preposition. This is exemplified by ( $3 b)$, which has (3a) as a structural alternative with the same meaning. ${ }^{6}$

$$
\begin{aligned}
& \text { a. uit naam van mij } \\
& \text { out name of me } \\
& \text { 'on behalf of me' }
\end{aligned}
$$

b. namens mij
name-en-s me
'on behalf of me'

Other pairs displaying this alternation in form are: (i) van wege (lit.: of way-e 'because of'), wegens (lit.: way-en-s), (ii) uit kracht van (lit.: from force of 'by virtue of'), krachtens (lit.: force-en-s); (iii) ten tijde van (lit.: by time of 'during'), tijdens (lit.: time-en-s).

Having introduced some of the distributional properties of adverbial $-s$, I will now turn to some of its morphosyntactic properties. In line with intuitions of traditional grammarians, I take expressions featuring adverbial $-s$ to have a composite structure. One might object to this and argue that these adverbs no longer have any internal structure in present-day Dutch, even though, historically, they arguably had. Under such an approach, these adverbs ending in $-s$ would be non-decomposable lexical units. In what follows, I will give some initial support for the idea that these expressions have an internal syntactic structure, though. In Sects. 4, 5 and 6, a more detailed discussion of the internal syntax of these (and other) expressions will follow.

Let me start out with the observation that adverbs ending in $-s$ display signs of structure, in the sense that discrete, meaningful units can be identified within the adverb. The fact that these units can sometimes alternate with other units-in/op in (4), gronds/hands and onder/boven in (5), na(a)m 'name'/kracht 'force' in (6) - hints at the decomposability of these adverbs. Here are some examples: ${ }^{7}$
a. ineens
$\mathrm{a}^{\prime} . \quad$ in $>$ een $>\mathrm{s}$
'at once'
b. opeens
$\mathrm{b}^{\prime} . \quad$ op $>$ een $>\mathrm{s}$
'at once'
a. ondergronds $\mathrm{a}^{\prime}$. onder $>$ grond $>\mathrm{s} \quad$ 'underground, subterranean'
b. onderhands
$\mathrm{b}^{\prime}$. $\quad$ onder $>$ hand $>\mathrm{s}$
'underhand'
c. bovengronds
$\mathrm{c}^{\prime}$. $\quad$ boven $>$ grond $>\mathrm{s}$
'overground'
d. bovenhands
$\mathrm{d}^{\prime}$. boven $>$ hand $>\mathrm{s}$
'overhand'
a. namens
$a^{\prime} . \quad$ naam $>$ en $>$ s
'on behalf of'
b. krachtens
$\mathrm{b}^{\prime}$. $\quad$ kracht $>$ en $>\mathrm{s}$
'by virtue of'

A second sign of structure comes from example (7). The adverb straks 'soon' clearly falls apart in pieces (i.e., strak $+-s$ ) when the diminutive suffix is part of the structure:

$$
\begin{array}{ll}
\text { a. } & \text { straks } \\
& \text { soon-s } \\
\text { 'soon' }
\end{array}
$$

$$
\begin{aligned}
& \text { b. } \quad \text { strak-je-s } \\
& \text { soon-DIM-s } \\
& \text { 'soon' }
\end{aligned}
$$

\footnotetext{
${ }^{6}$ The -en following nam- (3b) used to be a dative case in older Dutch (Van der Sijs 2010).

${ }^{7}$ In (4)-(7), and also in later examples, I often use Dutch orthographic conventions, which means that the adverbs are written as single units. Importantly, these units have an inner syntactic organization.
} 
A third sign of internal structure comes from phonological stress. Many adverbs ending in $-s$ display a stress pattern that corresponds to the one found in syntactic phrases. They display a phrasal stress pattern - that is, stress on the most deeply embedded (overt) constituent on the recursive side (Cinque 1993) — rather than a compound stress pattern - that is, stress on the first element of a complex word. This is exemplified in (8), where phonological stress is indicated by small capitals:
a. Deze bijen overwinteren onderGRONDS. these bees hibernate under-ground-s
b. Deze bijen overwinteren onder de GROND. these bees hibernate under the ground
c. De ONDERgrond is te hard. the subsoil is too hard

(8a) exemplifies the adverb featuring adverbial $-s,(8 b)$ illustrates the stress pattern of a syntactic phrase, and (8c), finally, show the stress pattern that is characteristic of Dutch compounds. Clearly, the stress pattern in (8a) sides with the one in (8b), which suggests that ondergronds has a phrasal structure, as in (9). As I will argue later, gronds can be further decomposed into smaller units: grond $+-s$.

(9) [PP onder [gronds]]

A fourth indication that adverbial expressions featuring adverbial $-s$ have an internal phrase structure, comes from substitution; that is, a pro-form can replace a subpart of the adverbial expression. Consider example (10), where both the $-s$ attached to kamer and the $-s$ interspersed between binnen and kamers represent adverbial $-s$; see Sect. 4.3 for further discussion.

(10) De minister liet binnenskamers en daarbuiten weten te willen the minister let inside-s-room-s and there-outside know to want vasthouden aan haar plan.

stick to her plan

'The minister informed people, both behind closed doors and in public, that she wanted to stick to her plan.'

In (10), daar refers to kamers, a subpart of binnenskamers. The fact that this coreference relation is possible suggests that the expression binnenskamers has a phrasal structure rather than the structure of a complex word. A nominal subpart of a complex word typically does not enter into a coreference relationship with an external antecedent. This is exemplified in (11):

De luis zat $\left[\right.$ op een $\left[\right.$ kamer $_{\mathrm{k}}+$ plant $\left._{\mathrm{j}}\right]$. Hij zat daar $\mathrm{r}_{\mathrm{j}}$ k $_{\mathrm{k}}$ al een uur. the green-fly sat on a room+plant he sat there already an hour 'The green fly sat on a house plant. It had been there $\left({ }^{\mathrm{OK}}(\mathrm{on})\right.$ the house plant/*(in) the room) for an hour.'

Daar can only refer to the noun phrase een kamerplant, and not to the subpart kamer of the noun kamerplant. 
A final sign of internal structure comes from the grammatical behavior of adpositional phrases featuring a preposition ending with adverbial $-s$. Specifically, this behavior concerns the phenomenon of R-pronominalization. As noted in van Riemsdijk (1978), a pronominal complement of an adposition occurs to the left of that adposition and converts morphologically into a so-called R-pronoun (i.e., a pronoun featuring the sound $/ r /$ ). According to his analysis, a pronoun starts out in the complement position of a preposition (i.e., P + PRON; e.g. op wat 'on what') and moves to the specifier position of $\mathrm{P}$, which yields the postpositional word order (i.e., [PP $\left.\left.\mathrm{PRON}_{\mathrm{i}}\left[\mathrm{P}, \mathrm{Pt}_{\mathrm{i}}\right]\right]\right)$. It is in the specifier position that the pronoun gets converted into an R-pronoun; for example, wat $+o p$ (what on) gets converted into waar $+o p$ (where on 'on what?'). An example is given in (12):

[Waar op $] / ?$ ? $[$ p wat $]$ stond Jan?

where on / on what stood Jan

'What did Jan stand on?'

With this as background knowledge, consider now example (13):

[Tijdens wat] / *[Waar tijdens] moest jij vreselijk niezen?

during what/ where during had-to you terribly sneeze

'During which event did you have to sneeze so terribly?'

(13) shows that tijdens does not display the grammatical behavior of a regular adposition. Specifically, leftward placement of the pronoun and subsequent R-conversion are impossible. From this non-adpositional behavior I conclude that tijdens should not be analyzed as a non-decomposable adposition. Rather, it has a composite structure (tijden-s). It is this more complex internal structure that accounts for the impossibility of having leftward displacement and subsequent R-conversion of the pronoun; see Sect. 4.2.

In sum, many so-called adverbs ending in adverbial $-s$ have an internal organization. They are complex syntactic objects. One of the elements of the composite structure is the adverbial marker $-s$. In Sect. 3, I examine more closely the grammatical nature of this small element.

\section{Adverbial - $s$ as a last resort manifestation of categorial $n$ and $a$}

If adverbs featuring adverbial $-s$ have an internal syntax, what is the grammatical nature of $-s$ ? In traditional grammar (Royen 1947-1954:48), it is noted that adverbial $-s$ was a genitival case originally. Since genitival case appeared on a large number of words having an adverbial function, it was considered to be an adverbial suffix; that is, a suffix that turns a word of category $\mathrm{Y}$ into an adverb. For example, the noun dood 'death' in (1c) converts into an adverb after attachment of $-s$. Of course, fulfilling a certain grammatical function (in casu adverbial modification) does not imply that the word or phrase carrying out that function belongs to a particular part of speech. For example, the fact that the English word fast can be used adverbially, as in John drove fast, does not lead to the conclusion that it is a category belonging to the part of speech type 'adverb' (Emonds 1976, 1987a). Clearly, fast can fulfill 
other grammatical functions, such as predicative complement (This car is fast) and attributive modifier ( fast car). Likewise, linguistic expressions carrying adverbial $-s$ can have different grammatical functions, as illustrated in (14) for the Dutch word anders (other-s, 'different(ly)'). Next to being a manner adverbial, as in (14a), it can function, for example, as a predicate selected by a copular verb (14b).
a. $\mathrm{Na}$ de operatie liep Jan anders. after the surgery walked Jan different-s 'After surgery Jan walked differently.'
b. Jan is anders dan de rest van zijn klas. Jan is different than the rest of his class 'Jan is different from the other children in his class.'

If a word's categorial (i.e., part of speech) status does not follow from its grammatical function within a larger syntactic configuration (e.g., a clause), we are back to our original question: What is the grammatical nature of $-s$ ? My answer to this question builds on the idea that lexical categories such as nouns, adjectives and verbs have the composite structure $\mathrm{f}+$ Root, where $\mathrm{f}$ is a categorial head (e.g., $n, a, v$ ) and the root is unspecified as to category (Marantz 1997; Harley and Noyer 1999; Borer 2005). Specifically, I propose that adverbial $-s$ instantiates the categorizing head $n$, and, as we will see in Sect. 6 , the categorial head $a$. Of course, if $-s$ is a manifestation of the categorizing head $n$, the question arises as to when it surfaces. It clearly does not pop up in all nominal environments. For example, $-s$ is impossible in (15a) but obligatorily present in (15b):

$$
\begin{aligned}
& \text { a. in één }\left(*_{-s}\right) \operatorname{keer}\left(*_{-s}\right) \\
& \text { in one time } \\
& \text { 'at once' }
\end{aligned}
$$$$
\begin{aligned}
& \text { b. ineen*(-s) } \\
& \text { in-one-s } \\
& \text { 'at once' }
\end{aligned}
$$

The contrast in (15) suggests that the appearance of $-s$ correlates with the absence of an overt root. When there is an overt root (keer), the appearance of $-s$ is blocked, as in (15a). On the contrary, when there is no overt root, $-s$ must surface, as in (15b).

In Sects. 4-6, I will discuss various nominal and adjectival patterns in which adverbial $-s$ surfaces. Before exploring each of them, I think it is helpful to introduce already here the abstract configurations that feature $-s$. But let's first briefly discuss the pattern in which $-s$ does not surface, as in (15a). A basic assumption, already mentioned before, is that nouns have the base form $n+\operatorname{root}(=\sqrt{ })$, where 'root' starts out as the complement of $n$. The noun is "created" (derived) by head-moving the root to the categorizing head $n$, which I take to be an affixal element. The amalgam $[$ root $+n]$ is conventionally taken to be a complex head in which the raised root is adjoined to $n$, yielding the complex head $[n$ root $+n]$. To make things more concrete: head-movement of $\sqrt{ }$ keer to $n$ in (15a) yields the complex head $[n \sqrt{ } k e e r+n]$. Following Chomsky (2015:12), however, I depart from this conventional analysis of the complex head and will assume that the affixal categorizing head $n$ is adjoined to the raised root. ${ }^{8}$ I will further adopt Chomsky's proposal that the root, even though being

\footnotetext{
${ }^{8}$ Chomsky's (2015:12) proposal is based on the behavior of the affixal categorizing head $v^{*}$. He proposes that when $v^{*}$ is adjoined to the root $\mathrm{R}$, it is invisible to the labeling algorithm.
} 
the host of the affix, cannot label, and that it is the amalgam 'root+categorizer' that plays a role in labeling (the projected structure).

As argued in Chomsky (2015:12), the categorizing affix adjoined to the root is invisible to the labeling algorithm, which determines the properties of the syntactic object that results from merger of the root with the categorizing affix (Chomsky 2013). Building on this proposal, I propose that $n$, being an affix adjoined to a (freemorphemic) root (e.g., $\sqrt{ }$ keer $)$, is invisible for last resort Spell-out at the Syntax-PF interface. Consequently, the categorizing affix $n$ does not externalize as $-s$, whence the ill-formedness of in één keer-s (see (15a)). ${ }^{9}$

Let us next turn to the configurations in which the categorial head $n$ does surface as $-s$. I propose that externalization of $n$ as $-s$ relates to the nature of the amalgam root $+n$, and especially to the nature of the root. Specifically, I take there to be two contexts in which the categorizing head must surface. Firstly, $n$ externalizes as $-s$ when the raised root is silent (e.g., $\sqrt{ }$ TIME), as in $(15 \mathrm{~b}) .{ }^{10}$ The intuitive idea here is that, in a complex head, at least one of the subparts must externalize at PF. ${ }^{11}$ If the root does not materialize (i.e., spell out overtly), then $n$ must: $[\sqrt{ } T I M E+n(=-s)]$. This means that the appearance of $-s$ in a structural context like (15b) is a last resort operation (Chomsky 1986, 1995). Let's call it '-s-Support.' One might want to relate the need to insert $-s$ to the principle of recoverability: $-s$ must be inserted in order to make the information that we are dealing with a nominal construct (i.e., nP) formally recoverable at the sound surface.

The second configuration in which $n$ externalizes as $-s$ is one in which the raised root is a Bound-Morphemic element instead of a free morphemic element. In other words, we have the following amalgam: $\left[\sqrt{B M}_{B}+n_{\text {affixal }}\right]{ }^{12}$ I assume that in this exocentric head-head configuration, where the subparts share the property of being bound morphemes, the two heads must conjointly externalize at PF. ${ }^{13}$ In a way, their mutual dependence_-both being bound-morphemes - requires the two elements to materialize together, yielding a single lexical unit at the surface. Also here, I take externalization of $n$ as $-s$ to be a last resort operation: $-s$-Support must take place in order to externalize the exocentric complex head.

\footnotetext{
${ }^{9}$ I assume that the ill-formedness of in één-s keer (see (15a)) is due to the fact that the root (keer) has not raised to affixal $n$. If the root does not raise, there is no host for $n$ to attach to. Furthermore, the root, remaining in situ and consequently being uncategorized, is an uninterpretable element in the syntactic representation. As noted by Chomsky (2015), raising of the root to a categorizing head is a universal property of language.

${ }^{10}$ Importantly, I assume that the amalgam $[\sqrt{ } T I M E+n]$ is a legitimate (i.e., interpretable) construct at the syntax-LF interface. Thus, realization of $n$ as $-s$ is a phenomenon at the syntax-PF interface. It should be noted that $-s$ does not seem to contribute any meaning to the adverbial pattern in which it is embedded.

${ }^{11}$ As an alternative, one might consider an analysis in which $-s$ spells out the entire complex head, that is: $[\sqrt{ } n(=-s) \sqrt{ }$ silent $+n]$. As will become clear soon, there are patterns in which $n$ spells out when the root has phonological contents. In those cases, it is clear that $-s$ externalizes a subpart of the complex head. I will therefore assume that it is always the categorizer $n$ that materializes.

${ }^{12}$ The existence of bound roots is familiar from examples such as English $\sqrt{ }$ struct, as in instruct and construction.

${ }^{13}$ In a way this is reminiscent of Chomsky's (2013) proposal that in an exocentric XP-YP-configuration, $\mathrm{X}$ and $\mathrm{Y}$ can be taken as the label of this syntactic object if $\mathrm{X}$ and $\mathrm{Y}$ are identical in a relevant respect (e.g., by sharing a certain feature).
} 
In order to make things more concrete, let me give an illustration of this second configuration in which $-s$-support takes place, namely the indefinite pronominal iets 'something' (see Sect. 5.2). This pronominal has a composite structure: iet $+-s$. The first part never occurs on its own in present-day Dutch: *iet. I take this element to be a bound root which, after being raised to (affixal) $n$, creates the following complex exocentric head: $\left[\right.$ jiet $\left._{B M}+n_{\text {affixal }}(=-s)\right]$.

Summarizing, I have proposed that the appearance of adverbial $-s$ depends on the nature of the root that merges with $n$. A raised free root (e.g., $\sqrt{ }$ keer) yields a complex head in which the root constitutes the host for categorial $n$. A raised silent root, as in ineens (15b), yields a complex head in which $n$ externalizes as $-s$ as a last resort. Finally, a raised bound root (e.g., iet) yields an exocentric complex head, whose subparts, being bound morphemes, must externalize conjointly, where externalization of affixal $n$ is a last resort operation.

So far, I have argued that $-s$ is a last resort realization of the categorizing head $n$ (and also $a$; see Sect. 6). A question which has not been answered yet is the following: Why $-s$ as an externalization of $n$ (and $a$ )? My answer to this question starts from the traditional grammarians' claim that so-called adverbial $-s$ relates to genitival case. Specifically, I build on Emonds's (1985, 1987b) proposal that genitival caseand Case, more generally - is not an independent, primitive category but rather an affixal realization of a part of speech (see also Pesetsky 2013). In Emonds's formulation, Case is an alternative realization of the categorial head that selects a noun phrase as its complement. For example, a noun marked for genitival case, as in Latin domus puellae (house girl-GEN, 'the girl's house') is a noun carrying a nominal suffix, here represented as ' $\mathrm{N}$ ': ${ }_{N}$ domus $]$ puell $\left[{ }_{N}-a e\right] .{ }^{14}$ Although genitival case (i.e. Noun $_{\text {affixal }}$ ) normally surfaces ex situ on a satellite constituent of the noun, I propose that it can also surface in situ as a last resort strategy. Under the above-mentioned assumption that nouns have the base form $n+$ root, genitival case equals affixal $n$. Socalled adverbial $-s$ is then a last resort in situ realization of affixal $n$ (and affixal $a$, as we will see in Sect. 6). ${ }^{15}$

Having shown that adverbs featuring adverbial $-s$ are syntactic constructs with an inner structure (Sect. 2) and having proposed that adverbial $-s$ is a last resort manifestation of the categorizing head $n$, I now turn to three case studies on adverbial $-S$.

\footnotetext{
${ }^{14}$ The element $-s$ no longer shows up productively on a satellite constituent of the noun. There is a small set of nominal expressions, though, in which a noun appears to assign genitive case to its complement, as in possessive noun phrases such as de heer des huizes (the lord the-GEN house-GEN, 'the master of the house') and de tand des tijds (the tooth the-GEN time-GEN, 'the test of time'). These are, however, fixed idiomatic expressions. An expression like *de fiets des jongens (the bike the-GEN boy-GEN, 'the boy's bike') is impossible in present-day Dutch. For a brief remark on the use of $-s$ on prenominal possessors, as in Jans fiets (Jan-s bike, 'Jan's bike'), see Sect. 7.

${ }^{15}$ See Rouveret and Vergnaud $(1980)$, Chomsky $(1981,1986)$ for the idea that nouns (N) and adjectives (A) are the syntactic categories involved in assignment of genitival case.
} 


\section{Three configurations featuring adverbial -s}

\subsection{Adverbial -s in manner adverbial expressions}

The first case study on adverbial $-s$ concerns manner expressions such as zachtjes in (16a). As the gloss indicates, three components can be identified in this type of adverbial expression: the adjective (zacht), the diminutive morpheme -je, and adverbial $-s$. Note that the appearance of $-s$ is obligatory. The b-examples show that this pattern is quite productive in Dutch. ${ }^{16}$
a. Jan loopt zacht-je*(-s).
Jan walks slow-DIM(-s)
'Jan walks slowly.'
b. voorzichtigjes 'carefully,' boosjes 'angrily,' langzaampjes 'slowly,' vlugjes 'quickly,' sloompjes 'indolently,' traagjes 'slowly,' stilletjes 'quietly', et cetera

The occurrence of -je right after the adjective is quite remarkable given the fact that -je typically attaches to nouns (17), and not to attributive (18a) or predicative (18b) adjectives.

Dit is een zacht matrasje.

this is a soft mattress-DIM

'This is a soft (little) mattress.'
a. een zacht $(* j e)$ matras
a soft(DIM) mattress
b. Dit matras is zacht / *zachtje.
this mattress is soft / soft-DIM

This raises the question as to whether the pattern zachtjes contains a hidden noun. I will argue that this is indeed the case. But before discussing the presence of such a hidden noun, I will first examine the adjectival part of this linguistic expression. It should, first of all, be noted that, if $-j e$ is absent and we have a bare adjective, $-s$ cannot appear. Thus, the presence of $-s$ correlates with the presence of the diminutive morpheme $-j e .{ }^{17}$

$$
\begin{aligned}
& \text { Jan loopt zacht }\left(*_{-s)}\right. \text {. } \\
& \text { Jan walks slow(-s) } \\
& \text { 'Jan walks slowly.' }
\end{aligned}
$$

\footnotetext{
${ }^{16}$ The sequence -jes (-DIM+s) is also found after elements that are non-adjectival (e.g., saampjes, saam + pje+s, 'together'), or appear to be so (e.g., alleentjes (alleen+tje+s, 'alone'); weinigjes (little-DIMs, 'little/a bit'). The element saam- is also attested in samen (saam+-en, 'together') and saamhorig ('solidary'). The elements alleen and weinig are adjectival after all, given the fact that they can be modified by degree words such as erg 'very,' as in erg alleentjes/weinigjes ('very lonely/very little').

${ }^{17}$ The ungrammaticality of zachts is another illustration of the fact that a categorizing head $(a)$ does not surface as $-s$ when the root $(z a c h t)$ is a free morpheme: $\left[[z a c h t]+a\left(=*_{-s}\right)\right]$.
} 
As exemplified in (20), the adjectival component can be complex, that is, have a phrasal syntax. This is shown by the fact that zacht can be accompanied by a degree modifier:
Jan liep [te/zeer/erg/even zachtjes].
Jan walked too/very/very/as slow-DIM-s
'Jan walked too/very/as slowly.'

Example (21) shows that the free comparative morphemes meer 'more' and minder 'less' can also modify the adjective:

Ze zag [net iets meer /minder bleek-je-s] (dan normaal). she looked just a-little more /less pale-DIM-s than normally 'She looked a bit more/less pale than she normally does.'

The bound comparative morpheme -er, however, cannot combine with zachtjes. Both the sequence A-COMPAR-DIM-s (22a) and the sequence A-DIM-COMPAR-s (22b) are ruled out: ${ }^{18}$
a. *Jan rijdt nu [nog zacht-er-tje-s] Jan drives now even slow-COMPAR-DIM-s 'Jan drives even more slowly now.'
b. ?* Jan rijdt nu [nog zacht-je-s-er].

Notice, finally, that, while a PP-complement can easily combine with the bare adjective bang, as in (23a), such a combination is less acceptable when we have the adverbial form bangetjes (i.e., bang-DIM-s); see (23b):
a. [AP Bang [PP voor mijn kritiek]] kwam Jan schoorvoetend de kamer afraid of my criticism entered Jan reluctantly the room binnen. PRT 'Fearing my criticism, Jan entered the room reluctantly.'
b. $\quad ? *[\mathrm{AP}$ Bangetjes [PP voor mijn kritiek]] ......

The above-mentioned data suggest that the appearance of adverbial $-s$ and the inner morphosyntactic behavior of the adverbial expression are rule-governed. With these data as our empirical basis, let us next address the question as to what the internal syntax of these expressions is. As already noted, the diminutive morpheme -je is best known for its suffixal attachment to nouns, as in matras-je (17) and tafeltje (table-DIM, 'small table'); see Wiltschko (2005), De Belder (2011). Attachment of the diminutive morpheme to the noun does not change the categorial status of the newly built complex construct. ${ }^{19}$ Thus, tafeltje constitutes a nominal construct, just

${ }^{18}$ Certain speakers of Dutch permit the form netjeser (net+DIM+s+COMPAR, 'properly/decently'). They
often also permit netjes as an attributive adjective: een netjes iemand 'a decent person'. Possibly, the
diminutive morpheme in this pattern is a "low" diminutive in the sense of De Belder et al. (2014); that is,
a derivational suffix involved in word syntax rather than a functional head involved in phrasal syntax.
${ }^{19}$ Attachment of the diminutive morpheme has an effect on gender in Dutch: nouns carrying the diminu-
tive morpheme are [+neuter]. Thus the [-neuter] noun tafel 'table' (e.g. de tafel) becomes [+neuter]: het 
like tafel 'table'. This is further confirmed by the fact that it can be followed by a plural morpheme (in casu: -s), just like tafel: tafels (table-PL), tafeltjes (table-DIM-PL). From this grammatical behavior of the diminutive morpheme, it can be concluded that it is a nominal type of bound morpheme. This brings us to the next question: How does the diminutive morpheme combine with the adjective?

In line with Wiltschko (2005) and De Belder (2011), I propose that the Dutch diminutive marker -je is a functional head in the extended nominal projection. It contributes the meaning component 'smallness.' Given its quantity-related meaning, I label the projection headed by $-j e$ as QP, which I take to be a layer on top of $\mathrm{nP} .^{20}$ Thus, matrasje (mattress-DIM) in (17) has the base structure in (24a). Its surface form is derived by first raising the free root matras to $n$ (24b), and subsequently raising the amalgam [matras $+n$ ] to Q (-je), as in (24c). I added the representation in (24d) in order to show what the extended nominal projection looks like when QP is embedded in a larger noun phrase containing an attributive AP. As indicated, I assume that the attributive AP zacht occupies the Spec-position of a functional layer representing attributive modification (Cinque 1994).
a. $[\mathrm{QP}-\mathrm{je}[\mathrm{nP} \mathrm{n}[\sqrt{ }$ matras $]]]$
b. $\quad\left[\mathrm{QP}-\mathrm{je}\left[\mathrm{nP}[[\sqrt{ }\right.\right.$ matras $\left.\left.]+\mathrm{n}]\left[\sqrt{ }^{\text {matras }}\right]\right]\right]$
c. $[\mathrm{QP}[[[\sqrt{ }$ matras $]+\mathrm{n}]-\mathrm{je}][\mathrm{nP}[[\sqrt{ }$ matras $]+\mathrm{n}][\sqrt{ }$ matras $]]]$

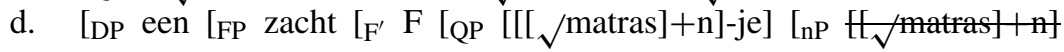 $[\sqrt{ }$ matras $]]]]]$

(24a) is the base structure. (24b) is the structure derived by root-to- $n$ movement, yielding the complex head $[[\sqrt{ }$ matras $]+n]$. $(24 \mathrm{c})$ is the structure derived by movement of the amalgam $[[\sqrt{ }$ matras $]+n]$ to the diminutive morpheme $-j e$. It yields the following structure: $[[[\sqrt{ }$ matras $]+n]+j e]$. (24d) represents the entire noun phrase containing the attributive AP zacht.

Let us now consider the structure of zachtjes. I propose it has the base structure in (25a) and the derived structure in (25b):

$$
\begin{array}{ll}
\text { a. } & {\left[\mathrm{FP} \text { zacht }\left[\mathrm{F}^{\prime} \mathrm{F}[\mathrm{QP}-\mathrm{je}[\mathrm{nP} \mathrm{n}[\sqrt{ } \mathrm{WAY}]]]\right]\right]} \\
\text { b. } & {\left[\mathrm{FP} \text { zacht }\left[\mathrm{F}^{\prime} \mathrm{F}[\mathrm{QP}-\mathrm{je}[\mathrm{nP}[\mathrm{n} \sqrt{ } \mathrm{WAY}+\mathrm{n}(=-\mathrm{s})] \mathbb{V} \text { WAY }]]\right]\right]}
\end{array}
$$

According to this analysis, zacht is an attributive AP that acts as a modifier within an extended nominal projection whose "noun" (i.e. root) is silent. ${ }^{21}$ From bottom to top, this projection consists of the following components: (i) a silent root encoding 'manner,' here represented as WAY, (ii) a categorizing head $n$ that selects the 'manner'

tafeltje. This gender change can be identified on the basis of the definite article: [-neuter, +singular] nouns combine with $d e$ 'the', [+neuter, +singular] nouns with het 'the'. Plural nouns always take de as their definite article.

${ }^{20}$ Wiltschko takes the German diminutive to be a classifier heading ClasP. De Belder analyzes Dutch -je as a Size-head heading SizeP. See Sect. 5.2 (on the Measure Phrase ietsjes) for an argument that -je occupies Q.

${ }^{21} \mathrm{My}$ analysis of zachtjes is similar in spirit to Déchaine and Tremblay's (1996) analysis of English -ly adverbs (e.g., quickly). They propose that quick is an attributive AP that modifies -ly, which they treat as a noun. See Kayne (2003) for the existence of silent nouns. 
root, (iii) the diminutive -je heading the QP-layer, and (iv) the attributive adjective phrase zacht in Spec,FP. ${ }^{22}$

As shown by (25b), the pattern zachtjes is derived by raising the silent root to $n$, which yields the amalgam $[\sqrt{ } W A Y+n]$. I assume that, in this complex head configuration featuring a silent root, the categorizing head $n$ externalizes as $-s$ as a last resort operation; that is, at least one of the subparts of the complex head must materialize at the syntax-PF interface. If the root does not externalize, $n$ must. I assume that the complex head $[\sqrt{ } W A Y+n]$, which features the silent root, does not raise and adjoin to the diminutive morpheme $-j e$ in $\mathrm{Q}$, possibly because the amalgam $[\sqrt{ } W A Y+n(=$ $-s)$ ] is phonologically to weak to act as a syntactic host for a diminutive suffix. ${ }^{23}$ Since $-j e$ and $-s$ are not united by means of syntactic head movement, I assume they are united by a post-syntactic merger operation in the sense of Embick and Noyer (2001). Specifically, the affixal diminutive element je undergoes string-vacuous (i.e., non-inverting) Local Dislocation, and concatenates with what follows, yielding the linear sequence $j e+-s$, which constitutes a syllable: /jəs/.

The analysis in (25) provides a straightforward account of the phenomena discussed in (20)-(23). First, it is expected that the adjective, being an attributive modifier in [Spec,FP], can be accompanied by a degree word, as in (20)-(21). Second, the pattern in (23b) is excluded for the same reason that the ill-formed noun phrase *een bange man voor kritiek (an afraid man of criticism, 'a man afraid of criticism') is, namely: a PP-complement can never be extraposed out of an attributive AP and be placed in the right periphery of the containing noun phrase. Schematically:
a. $\quad ?^{*}\left[\left[\mathrm{FP}\left[\mathrm{AP} \mathrm{t}_{\mathrm{k}}\right.\right.\right.$ bang $\left.]\left[\mathrm{F}, \mathrm{F}\left[\mathrm{QP}-\mathrm{etje}\left[\mathrm{nP}\left[\sqrt{ } \mathrm{WAY}_{\mathrm{i}}+\mathrm{n}(=-\mathrm{s})\right] \mathrm{t}_{\mathrm{i}}\right]\right]\right]\right][\mathrm{PP}$ voor mijn kritiek $\left.]_{\mathrm{k}}\right]$
b. $*\left[\left[\right.\right.$ een $\left[\mathrm{FP}\left[\mathrm{AP} \mathrm{t}_{\mathrm{k}}\right.\right.$ bange $\left.\left.]\left[\mathrm{F}, \mathrm{F}\left[\mathrm{nP}\left[\sqrt{ } \mathrm{man}_{\mathrm{i}}+\mathrm{n}\right] \mathrm{t}_{\mathrm{i}}\right]\right]\right][\mathrm{PP} \text { voor mijn kritiek }]_{\mathrm{k}}\right]$

\begin{abstract}
${ }^{22}$ One may wonder whether the nominal expression in $(25 b)$ is embedded within a larger PP headed by an empty preposition, as has been proposed, for example, by Bresnan and Grimshaw (1978), Emonds (1976, 1987b) and McCawley (1988) for English NP-adverbs such as my way (I did it my way) and last week (John left last week). Although it, certainly, is worthwhile to systematically explore the presence of this prepositional layer on top of the noun phrase, I will leave this issue for future research, due to space limitations. Let me give one argument, though, which seems to go against a PP-analysis for the manner adverb zachtjes. The argument comes from extraposition, that is the postverbal placement of a phrase in an (underlyingly) verb-final clause. Normally, PPs and CPs, but not NPs and APs, can occur in extraposed position in Dutch. For example, the PP op een slome manier 'in a sleepy way' can occur either preverbally or postverbally, as indicated (by $<>$ ) in (ia). As shown in (ib), zachtjes can only occur in preverbal (i.e., non-extraposed) position. This suggests that zachtjes is not embedded in a PP. Notice, by the way, that the bare temporal noun phrase die dag 'that day' can occur postverbally, which suggests that this phrase is embedded in a PP:
\end{abstract}

(i) a. ..dat hij de deur <op een slome manier $>$ opende <op een slome manier $>$. that he the door in a sleepy way opened

b. ...dat hij de deur <sloompjes $>$ opende $<*$ sloompjes $>$. that he the door sleepy-DIM-s opened

c. ..dat hij $<$ die nacht $>$ de deur sloompjes opende $<$ die nacht $>$. that he that night the door sleepy-DIM-s opened

${ }^{23}$ Such a raising operation would yield the ill-formed pattern zacht-s-je, in which the amalgam $[\sqrt{ } W A Y+n$ $(=-s)]$ is raised and adjoined to the diminutive morpheme in Q, yielding the complex head [[ $\sqrt{ } W A Y+n(=$ $-s)]+-j e]$. 
Third, the ill-formedness of (22b) follows from the fact that the bound comparative morpheme -er cannot attach to a nominal element, as depicted in (27):

$$
\text { [FP Zacht [F, F [QP -je } \left.\left.\left.\left[\mathrm{nP}[[\sqrt{ } \mathrm{WAY}+\mathrm{n}(=-\mathrm{s})](* \text {-er })] \mathrm{t}_{\mathrm{i}}\right]\right]\right]\right]
$$

(27) is ill-formed for the same reason that *een zacht matras-er (a soft mattressCOMPAR) is, namely: nouns do not act as hosts for a bound comparative morpheme. Comparative -er can only be hosted by an adjective: een zacht-er matras (a soft-COMPAR mattress, 'a softer mattress').

As for the ill-formed pattern *zacht-er-tje-s in (22a), I tentatively propose that it follows from the interaction between the synthetic-comparative form zachter and the QP -tje-s. ${ }^{24}$ Specifically, I take the former to be derived by movement of zacht to the bound comparative morpheme -er (i.e., $\mathrm{Q}_{[\text {compar] }}$ ) yielding the adjectival structure $[Q P$ zacht-er [AP an unpronounced copy). I propose that the bound-morphemic amalgam -tjes, which needs an overt host to its immediate left, cannot attach to zachter (via morphological merger) and form a phonological unit with it due to the presence of the trace (of displaced zacht). Schematically:

$$
\text { *[FP [QP Zacht-er [AP zacht] [F, F [QP -tje [nP } \left.\left.\left.\left.\left[\sqrt{ } / \mathrm{WAY}_{\mathrm{i}}+\mathrm{n}(=-\mathrm{s})\right] \mathrm{t}_{\mathrm{i}}\right]\right]\right]\right]
$$

This account of the ill-formed pattern zachtertjes is reminiscent of the ungrammaticality of wanna-contraction in sentences such as *Who do you wanna get the wine? (Compare: Who do you want to get the wine?). As has been argued in the literature, contraction of want and to to wanna is blocked as a result of an intervening wh-trace (Selkirk 1972):

$$
\text { Who do you want whe to get the wine? (contraction blocked) }
$$

The pattern minder bleekjes in (21) is well-formed for the simple reason that bleek remains in situ. The free comparative morpheme minder occupies (adjectival) Q, and, therefore, zacht does not raise and adjoin to Q. Since zacht remains in situ, there is a lexical host to which the bound morpheme -jes can attach via morphological merger.

$$
\text { [FP [QP minder [AP Zacht] } \left.\left[\mathrm{F}, \mathrm{F}\left[\mathrm{QP}-\mathrm{je}\left[\mathrm{nP}\left[\sqrt{ } \mathrm{WAY}_{\mathrm{i}}+\mathrm{n}(=-\mathrm{s})\right] \mathrm{t}_{\mathrm{i}}\right]\right]\right]\right]
$$

Summarizing, I have argued that the adverbial $-s$ at the end of the pattern zachtjes is an affixal realization of the categorizing head $n$. The last resort operation '-s-Support' is induced by the silence of the root in the amalgam $[\sqrt{ } W A Y+n]$.

\subsection{Adverbial -s on "prepositions"}

\section{Consider the italicized expressions in $(31):^{26}$}

\footnotetext{
${ }^{24}$ Note that positive adjectives ending in -er (e.g., dapper, 'brave') can be followed by the diminutive morpheme, as in dappertjes (brave-DIM-s, 'bravely'). From this, it can be concluded that the impossibility of zachtertjes is not a purely phonological thing. The grammatical nature of comparative -er matters.

${ }^{25}$ Note that I abstract away here from decomposition of AP into [aP a + Root]; see Sect. 6.

${ }^{26}$ Other examples of this pattern are the following: krachtens (force-en-s 'by virtue of'), behoudens (reservation-en-s 'except for'), wegens (way-en-s 'because of').
} 

a. Jan voerde namens de regering het woord. Jan carried name-en-s the government the word 'Jan spoke on behalf of the government.'
b. Er was tijdens de oorlog veel geweld. there was time-en-s the war much violence 'There was a lot of violence during the war.'

Traditionally, the italicized words are analyzed as prepositions featuring adverbial $-s$. In one important respect, though, these words do not behave like prepositions at all. As touched on briefly in Sect. 2, the complement cannot be pronominalized by a so-called R-pronoun and be placed before the adposition, yielding a postpositional pattern (van Riemsdijk 1978). ${ }^{27}$ This is shown in (32a,b), which are the Rpronominalized variants of $(31 \mathrm{a}, \mathrm{b})$.
a. *Jan voerde [daar namens] het woord. Jan carried there name-en-s the word 'Jan spoke on behalf of it/him/her.'
b. *Er was [er tijdens] veel geweld. there was there time-en-s much violence 'There was a lot of violence during it.'

The ungrammaticality of these examples suggests that these adpositions ending in -ens are not regular adpositions. Note at this point that R-pronominalization is possible with other adpositions heading an adverbial PP.
a. Jan voerde [daar voor] het woord.
Jan carried there for the word
'Jan spoke on behalf of it (e.g., the company).'
b. Er was [er na] veel geweld.
there was there after much violence
'There was a lot of violence after it.'

The question arises as to what causes the ill-formedness of the patterns in (32). As already hinted at by the glosses in (31) and (32), the "prepositions" ending in -ens contain a nominal element: naam 'name', tijd 'time'. The presence of this noun suggests that these "prepositional" elements are not simplex but have a composite structure. This composite structure becomes plausible when we consider the italicized patterns in $(34 a, b)$, which are the periphrastic counterparts of the synthetic forms namens and tijdens:

a. Jan voerde [PP in [NP naam [PP van de regering]]] het woord. Jan carried in name of the government the word 'Jan spoke on behalf of the government.'

b. Er was [PP ten [NP tijde [PP van de oorlog]] veel geweld. there was at time of the war much violence 'There was much violence during the war.'

\footnotetext{
${ }^{27}$ According to Van Riemsdijk, the R-pronoun occupies the specifier position of PP. In more recent analyses of the Dutch adpositional system, the R-pronoun occupies the specifier position of a designated functional projection; see Koopman (2000) and Den Dikken (2010).
} 
Given the fact that the periphrastic pattern and the synthetic pattern are quite similar in meaning and lexical make-up, it does not seem implausible to assign them the same underlying structure. Notice at this point that the periphrastic pattern features the element van, which marks a possessive relationship. In (34a), for example, the noun phrase de regering is the possessor and the noun naam the possessum. In the spirit of Longobardi's (2001) analysis of (the history of) French adpositional constructions featuring chez 'at' (e.g., chez Pierre, 'at Jean's place'), I propose that expressions such as namens de regering also encode a possessive relationship. Specifically, they instantiate the so-called Construct State (CS) pattern (Ritter 1988; Siloni 1996; Borer 1999), which is familiar from Semitic languages such as Hebrew. As shown in (35), Hebrew can express a possessive relationship in two ways, namely by means of a so-called free genitive construction featuring a dummy case marker shel, as in (35a), or by means of a CS-construction like (35b), which involves no such case marker.
a. ha-bayit shel ha-mora
the-house of the-teacher
'the teacher's house'
b. beyt ha-mora
house the-teacher
'the teacher's house'

Besides the presence versus absence of shel, there is another characteristic that distinguishes the free genitive construction from the CS-construction, namely the morphophonological form of the possessum-noun. In (35a), we have the free form bayit, in (35b) the CS-form beyt, which loses its main stress. This formal distinction is mirrored by the Dutch constructions in (31a) and (34a): the latter construction features the (free) form naam, the former construction the form namen (=naam+-en), which cannot occur on its own.

I propose that namen is a complex word consisting of the root $\sqrt{ } n a(a) m$ and the bound morpheme -en. More specifically, I take -en to be a "low" bound morpheme, that is, a morpheme structurally located in between $\mathrm{n}(\mathrm{P})$ and the root. Schematically: ${ }^{28}$

$$
[\mathrm{nP} \mathrm{n}[\mathrm{LexP}-\mathrm{en}[\sqrt{ } \mathrm{na}(\mathrm{a}) \mathrm{m}]]]
$$

I assume that the categorial head $n$ demarcates a frontier between two different structural domains (see also Harley and Noyer 1999; Marantz 1997; De Belder et al. 2014). The domain below categorial $n$ is reserved for lexical-that is, noncompositional, semantically unpredictable-meaning, whereas the domain above $n$ hosts functional projections contributing compositional-that is, non-idiosyncratic, predictable-meaning. Another (related) property that distinguishes "low" (i.e., below $\mathrm{n}$ ) and "high" (i.e., above $n$ ) grammatical formatives concerns productivity. Low grammatical formatives are not morphologically productive - that is, they apply only to a closed set of roots-whereas high grammatical formatives are.

\footnotetext{
${ }^{28}$ Following De Belder et al. (2014), whose proposal builds on Lowenstamm (2014), I assign the label 'LexP' to this derivational layer in between the root and the nP-layer.
} 
Starting with the latter property-morphological productivity-I conclude on the basis of the examples in (37) that the formation of possessive constructions featuring root $+e n-s$ is non-productive:
a. op verzoek van de regering
$\mathrm{a}^{\prime}$. *verzoek-en-s de regering at request of the government 'at the request of the government' request-en-s the government
b. op bevel van Hare Majesteit at command of Her Majesty
$\mathrm{b}^{\prime}$. *bevel-en-s Hare Majesteit 'by order of Her Majesty'
c. ten koste van de kwaliteit at expense of the quality 'at the expense of the quality'
$c^{\prime} . \quad *$ kost-en-s de kwaliteit

The impossibility of the examples in $\left(37 a^{\prime}-c^{\prime}\right)$ shows that the CS-pattern in (31) is a non-productive one.

Let's next turn to the first property: non-compositional meaning. Although one may still recognize some of naam's original meaning (i.e., 'name') in namens, it is quite clear that its meaning has become more abstract, as is also clear from its English translation: 'on behalf of.' Another illustration of a 'root-en-s' form, whose original meaning (namely: 'way') is no longer present, is the form wegens (way-en-s 'because of'), which designates the cause or reason of something, as in wegens de storm 'because of the storm'.

The question as to what the element -en contributes to this more abstract meaning obviously arises. I propose that, in present-day Dutch, -en is a derivational morpheme with a classifier-like function. Specifically, I assume it has a dividing function in the sense of Borer (2005:109-112); it portions out the mass denoted by the root and turns it into a unit. ${ }^{29}$ As such, -en in (31) has essentially the same role as the (singular) indefinite article een ' $a$ ' in the noun phrase een naam 'a name.' Interestingly, and maybe not surprisingly, the bound morphemic -en in namens has the same phonological form as the indefinite article een ' $a$ ' in a noun phrase like een naam (a name), namely /ən/. I propose that -en in namens is a "low" (i.e., derivational) classifier, while the indefinite article een is a "high" classifier, that is, a classifier representing a functional category within the extended nominal projection. I take this "high" classifier to be located right above the nP-layer: $[\mathrm{ClP}$ een $[n P n[\sqrt{ }$ naam $]]] .{ }^{30}$

Having argued that -en in namens is a classifying bound morpheme that turns a root into a unit, let me give some evidence in support of this unit interpretation of the bound morpheme -en. Consider the following examples:

\footnotetext{
${ }^{29}$ The underlying assumption here is that the mass reading is the default reading of a root; see Borer (2005).

${ }^{30}$ Note the parallel with diminutives. As De Belder et al. (2014) have argued, a distinction should be made between "high" diminutives, which occupy a functional head, and "low" diminutives, which are derivational morphemes occupying the head position of LexP. Interestingly, Wiltschko's (2005) interpretation of diminutives as being classifiers, leads us to conclude that the distinction between "low" classifiers and "high" classifiers is a more general phenomenon.
} 
a. Jan woont in het Zuiden/Noorden/Westen/Oosten/midden van

Jan lives in the South/North/West/East/middle of

Nederland. ${ }^{31}$

Netherlands

'Jan lives in the South/North/West/East/middle of the Netherlands.'

b. Jan woont in Zweden/Polen/Mechelen/Groningen/Leiden. ${ }^{32}$

Jan lives in Sweden/Poland/Mechelen/Groningen/Leiden

c. Jan reed iets naar achteren / voren.

Jan drove somewhat to back-en / front-en

'Jan drove a little backwards/forwards.'

d. De trein vertrekt iets na enen /iets na vieren.

the train leaves a.little after one-en /a.little after four-en

'The train will leave a little after one o'clock/a little after four o'clock.'

e. Jan vertrok gisteren.

Jan left yesterday

In $(38 \mathrm{a}, \mathrm{b}, \mathrm{c})$, the bound morpheme -en represents a unit of the class "spatial location." In (38a) we have a location defined in terms of a compass point, in (38b) a geographical location representing a country (Zweden, Polen) or a city (Mechelen, Groningen, Leiden), and in (38c) a location defined in terms of a spatial point: 'the back (side),' 'the front (side).' In (38d,e), -en represents a unit of the class 'temporal location/time." The phrase na enen in (38d) can be paraphrased as na één uur (after one hour, 'after one o'clock') and na vieren as na vier uur (after four hour, 'after four o'clock'). ${ }^{33}$ In (38e), -en represents a temporal unit of the type 'day,' as is also suggested by its English equivalent: yester-day.

A striking feature of the examples in (38) is, of course, the (obligatory) absence of -s after -en. The pattern na enen-s, for example, is impossible (compare with (38d)). I tentatively propose that this is due to the fact that -en in (38) is not a classifying derivational morpheme - so it is not the head of LexP — but rather an indefinite article that is used pronominally and substitutes for the entire functional projection CIP. Thus, na enen in (38d) has the following structure: [PP na [QP één $[C l P-e n]]] .^{34}$

Having shown that forms such as namen (i.e., [naam + -en]) are non-productive (see (37)), and have a non-compositional meaning, I now turn to the derivation of the surface form namens, which must feature so-called adverbial $-s$. For this, let us return to the abstract representation in (36), which is repeated in (39a). Following De Belder et al. (2014), I assign the label LexP to the structural layer located in between the root and nP. This gives us the base structure in (39a). As indicated in (39b,c), I

\footnotetext{
${ }^{31}$ The element mid occurs also in phrases such as (tot) mid januari '(until) mid January' and complex words, as in de midvoor van dit voetbalelftal 'the center-forward of this soccer team.'

${ }^{32}$ That these forms have a composite structure is shown by the fact that the root can also be part of another complex form, as in een Zweed-s-e actrice (a Swede-s-INFL actress, 'a Swedish actress') and een Mechels-e herder (a Mechel-s-INFL shepherd, 'a Belgian Shepherd (Malinois) dog').

${ }^{33}$ The fact that -en co-occurs with één, as in na enen, shows that -en does not correspond to the Dutch plural marker -en, as in hoed-en (hat-s, 'hats'). This means that -en in na vieren is not a plural marker.

${ }^{34}$ I leave a systematic investigation of the patterns in (38) for future research. See Corver and van Koppen (2011) for the use of the indefinite pronoun -en (comparable to English one) as a pronominalizing element in certain varieties of Dutch.
} 
take the pattern namens to be the result of two movement steps: $\sqrt{ }$-to-Lex movement (39b), and $[\sqrt{ }+$ Lex $]$ to $n$ movement (39c).

$$
\begin{aligned}
& \text { a. } \quad[n P \mathrm{n}[\operatorname{LexP} \operatorname{Lex}(=-\mathrm{en})[\sqrt{ } \mathrm{na}(\mathrm{a}) \mathrm{m}]]] \\
& \text { b. } \quad[\mathrm{nP} \mathrm{n}[\operatorname{LexP}[\operatorname{Lex}[\sqrt{ } n a(a) m]-\mathrm{en}] \mathbb{V} \mathrm{na}(\mathrm{a}) \mathrm{m}]]] \\
& \text { c. } \left.\quad\left[{ }_{n P}[[L e x[\sqrt{ } n a(a) m]-e n]+\mathrm{n}(=-s)]\left[\operatorname{LexP} \operatorname{LLex}_{\operatorname{La}} \sqrt{ } \mathrm{na}(\mathrm{a}) \mathrm{m}\right]-e n\right][\sqrt{ } \mathrm{na}(\mathrm{a}) \mathrm{m}]\right]
\end{aligned}
$$

I propose that the amalgam $[[\sqrt{ } / n a(a) m]-e n]$ has the following structure: [Lex $[\sqrt{ } n a(a) m]-e n]$, as in (39b). The amalgam namen is a construct that cannot occur on its own within a larger syntactic structure; as such it displays the behavior of a bound morpheme. I take this bound-morphemic behavior to be caused by the derivational affix -en. Raising of the amalgam $[$ Lex $[\sqrt{ } n a(a) m]-e n]$ to the categorial head $n$, which I take to be affixal, yields the complex head $[[$ Lex $[\sqrt{ } n a(a) m]-e n]+n(=-s)]$ in (39c). With namen and $n$ both being bound forms, we end up with an exocentric head-head configuration, whose subparts share the property of being bound elements. I propose that in a configuration like this, namen and $n$ must externalize conjointly at PF. Their mutual dependence-both being bound elements-requires the two elements to materialize together, yielding a single lexical unit at the surface. I take externalization of $n$ as $-s$ to be a last resort operation: $-s$-support must take place in order to externalize the exocentric complex head.

Having given an analysis of the internal structure of nominal expressions such as namens, I can now give an account of the ill-formed examples in (32). As pointed out above, I assume that the pattern namens de regering represents a Construct State pattern, with namens being the Construct State nominal (the possessum) and de regering being the possessed nominal. As shown in (40a), I propose that de regering occupies the specifier position of a functional projection encoding possession (i.e., PosP). In line with Cinque (2005) and Shlonsky (2004), I take the surface pattern to be derived by means of phrasal movement of the possessum across the possessor, as in (40b). Specifically, $\mathrm{nP}$ (namens) raises to [Spec,DP], the edge position of the nominal expression, and moves on to [Spec,PP], which is a potential landing site for displaced material in Dutch (see van Riemsdijk 1978).

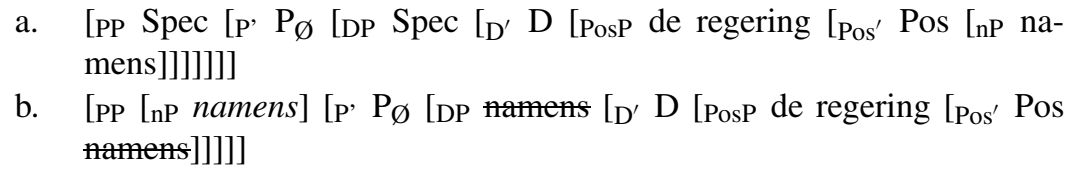

With nP namens occupying [Spec,PP], the ill-formedness of the examples in (32) follows straightforwardly: The R-pronoun daar (and also er) cannot occupy [Spec,PP], since this position is already taken by namens. In other words, the R-pronoun and namens compete for the same structural position. This is represented in (41a), where the demonstrative pronoun dat functions as possessor in [Spec,PosP]. This pronoun cannot move to [Spec,PP] and get converted into an R-pronoun, since namens already occupies this position. Notice also that movement of the possessor dat from [Spec,PosP] to [Spec,PP] would be impossible for reasons of locality (Chomsky's 2001 Phase Impenetrability Condition): Under a hypothetical structure like (41b), in which namens occupies [Spec,DP] rather than $[\mathrm{Spec}, \mathrm{PP}]$, displacement of dat to 
[Spec,PP] would violate PIC, because movement does not take place via the edge position (in casu the Spec-position) of the phase head D.

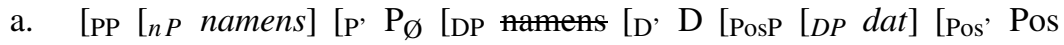 namens]]]]]]
b. *[PP daar [P, $\mathrm{P}_{\varnothing}\left[\mathrm{DP}\left[{ }_{n P}\right.\right.$ namens $]$ [D' D [PosP dat [Pos' Pos namens]]]]]

Summarizing, I have argued that the adverbial $-s$ that is part of apparent adpositions such as namens 'on behalf of,' is an affixal realization of the categorizing head $n$. Its appearance is induced by the bound-morphemic nature of the two subparts of the head-head amalgam, namely $n$ and the bound form namen.

\subsection{Adverbial -s in small nominal expressions}

This section examines the patterns ondergronds (under+ground $+\mathrm{s}$ ) and binnensmonds (inside-s-mouth-s). These patterns will be analyzed as adpositional structures that contain nominal expressions featuring adverbial $-s$. It will further be proposed that, when these patterns act as attributive prenominal modifiers, they do not behave like PPs but rather like adjectival phrases.

\subsubsection{The pattern $\mathrm{P}+\mathrm{N}+-\mathrm{S}$}

This section examines the italicized pattern $P+N+-s$ in (42). ${ }^{35}$
a. We bevinden ons nu onderGRONDS.
we find ourselves now under-ground-s
'We are underground now.'
b. We vertrokken bijTIJDS.
we left in-time-s
'We left in time.'
c. Jan vloekte binnensMONDS.
Jan cursed inside-mouth-s
'Jan was cursing silently.'

As indicated by the small capitals, phonological stress falls on the nominal element at the end of the italicized string. In Sect. 2, I already noted that this corresponds to a phrasal stress pattern and not to a compound stress pattern. Thus, the italicized patterns in (42) are constituents with a phrasal syntax.

Additional support for the syntactic nature of the italicized patterns in (42) comes from pronominalization. As shown in (43), an R-pronoun can substitute for the nominal component of the sequence $P+N+-s$ (e.g., kamers in (43a)). ${ }^{36}$ This substitution is similar in nature to the one attested in the minimal pair binnen de kamer (inside

\footnotetext{
${ }^{35}$ Observe that binnensmonds in (42c) also displays adverbial $-s$ in the middle of the linguistic expression. In traditional grammars, this $-s$ has been characterized as 'proleptic $-s$ '; it anticipates the appearance of the final $-s$. The nature of this proleptic $-s$ will be discussed in Sect. 4.3.2.

${ }^{36}$ See also my earlier discussion of example (10) in Sect. 2. The examples in (43) are drawn from the internet.
} 
the room) and daarbinnen (there-inside 'inside that/it'), where daar substitutes for the phrasal constituent (DP) de kamer.

a. [...] want binnenskamers mocht alles, daar buiten nog ... since inside-s-room-s was-allowed everything, there outside still steeds niets.

yet nothing

'... since, inside the house, everything was allowed, but, outside the house, nothing was permitted.'

b. De Wuzzi Alert biedt zowel binnenshuis als daarbuiten de the Wuzzi Alert offers both inside-s-house as there-outside the mogelijkheid om hulp in te roepen.

possibility for help PRT to call

'The Wuzzi Alert offers the possibility of requesting for help, both inside the house and outside of it.'

Given the surface similarity between the italicized patterns in (42), on the one hand, and the prepositional phrases onder de grond (under the ground), bij de tijd (by the time) and binnen de mond (inside the mouth) in (44), on the other hand, it is tempting to analyze the italicized elements in (42) as PPs. ${ }^{37}$ Notice that, just as in (42), the nominal element at the end of the prepositional structure in (44) carries phrasal stress, which is indicated by small capitals.
a. We bevinden ons nu onder de GROND. we find ourselves now under the ground 'We are under the ground now.'
b. Deze oude dame blijft bij de TIJD. this old lady stays at the time 'This old lady stays up-to-date.'
c. Er bevonden zich zweren binnen de MOND. there were REFL ulcers inside the mouth 'There were ulcers inside the mouth.'

A PP-analysis of the sequence $P+N+-s$ is supported by a number of grammatical properties. Firstly, the sequence can combine with (measure/degree) modifiers that are found in prepositional contexts, as in ruim/enkele meters/ver on de grond (am$\mathrm{ply} / \mathrm{several}$ meters/far under the ground). Some illustrations, drawn from the internet, are given in (45):

a. We zijn [ruim bijtijds] klaar. we are amply in-time ready 'We are ready well on time.'

\footnotetext{
${ }^{37}$ It should be noted that bij de tijd and bijtijds have a different meaning. The former means 'up to date,' the latter 'in time.' 
b. Er bevonden zich [enkele meters ondergronds] een aantal there were-located REFL some meters under-ground-s a number grafkamers.

tombs

'A number of tombs were located a few meters under the ground.'

c. Jouw mijmerplekjes bevinden zich nu [ver buitenshuis]. your daydream-spots are.located REFL now far outside-house 'Your places for day dreaming are far from home.'

Secondly, the word daar 'there' is a pro-form that can substitute for a locative PP, as in Jan woont in New York en Marie woont daar ook (Jan lives in New York and Marie lives there too). As shown in (46), daar can also substitute for the sequence $P+N+-s$.

(46) a. De echte attractie van dit klooster ligt ondergronds. Daar vind the real attraction of this monastery lies under-ground. There find je een lange gang vol kapellen en gebedsruimtes. you a long corridor full chapels and prayer-rooms 'The real attraction of this monastery is under the ground. There you find a long corridor with chapels and rooms for prayer.'

b. Bespreek dit binnenskamers, daar waar het hoort. discuss this indoors there where it belongs 'Please discuss this in a place where no one can hear you.'

Thirdly, the sequence $P+N+-s$ displays the distributional behavior of a PP. For example, PPs that function as modifiers within a noun phrase are typically postnominal. In this respect, they behave differently from attributive APs, which typically precede the noun. This contrast in distribution is clearly shown by an example like die [AP vreselijke] ruzie [PP binnen dat gezin] 'that terrible fight within that family.' As shown in (47), the sequence $P+N+-s$ can also be postnominal. Thus, distributionally it behaves like a PP. Another distributional property that hints at the prepositional status of $\mathrm{P}+\mathrm{N}+-\mathrm{S}$ is the fact that it can occur in postverbal position (the so-called PP-overV phenomenon; Koster 1975). This is shown in (48). In Dutch, only PPs and clauses (CPs) can occur in postverbal (i.e., extraposed) position.

a. [DP Dat gemompel binnensMONDS] stoort mij enorm. that murmuring inside-s-mouth-s annoys me enormously 'That inarticulate mumbling irritates me enormously.'

b. [DP Ruzie binnenSKAMERS] was er dus genoeg. quarrel in-door-s was there so enough 'So there were enough quarrels behind closed doors.'

(48) a. Guido heeft heel z'n leven hard gewerkt buitensHUIS. Guido has whole his life hard worked outside-house 'During his entire life, Guido worked hard outdoors.'

b. Heel stiekem wordt er toch gewerkt binnensKAMERS. very secretly is there PRT worked inside-room-s 'Nevertheless, people are secretly working indoors.' 
On the basis of the three above-mentioned prepositional characteristics, I conclude that the sequence $P+N+-s$ must be analyzed as a PP. This means that the examples in $(42 \mathrm{a}-\mathrm{c})$, which instantiate this pattern, have the base structures in $(49 \mathrm{a}-\mathrm{c})$ and the derived structures in $\left(49 \mathrm{a}^{\prime}-\mathrm{c}^{\prime}\right) \cdot{ }^{38}$ As indicated, I take the root to head-move to the categorial head $n$.

$$
\begin{array}{ll}
\text { a. } & {[\mathrm{PP} \text { onder }[\mathrm{nP} \mathrm{n}[\sqrt{ } \text { grond }]]]} \\
\mathrm{a}^{\prime} . & {[\mathrm{PP} \text { onder }[\mathrm{nP} \sqrt{ } \text { grond }+\mathrm{n}(=-s)[\sqrt{ } \text { grend }]]]} \\
\text { b. } & {[\mathrm{PP} \text { bij }[\mathrm{nP} \mathrm{n}[\sqrt{ } \text { tijd }]]]} \\
\mathrm{b}^{\prime} . & {[\mathrm{PP} \text { bij }[\mathrm{nP} \sqrt{ } \text { tijd }+\mathrm{n}(=-s)[\sqrt{ } \text { tijd }]]]} \\
\mathrm{c} . & {[\mathrm{PP} \text { binnens }[\mathrm{nP} \mathrm{n}[\sqrt{ } / \text { mond }]]]} \\
\mathrm{c}^{\prime} . & {[\mathrm{PP} \text { binnens }[\mathrm{nP} \sqrt{ } \text { mond }+\mathrm{n}(=-s)[\sqrt{ } \text { mond }]]]}
\end{array}
$$

The question arises as to why $n$ must surface phonologically. Importantly, $n$ does not surface as $-s$ when the complement of $\mathrm{P}$ is a full DP, as in onder de grond $\left(*_{-}-s\right)$, lit.: under the ground(-s). I propose that the appearance of $-s$ in linguistic expressions such as ondergronds relates to the nature of the root. Specifically, I take the root to be a bound root, that is: $\sqrt{ }$ grond $_{B M}$ ('BM' = bound morpheme). In this respect, it differs from the root grond in onder de grond, which I take to be a free morpheme. This distinction between $\sqrt{ }$ grond $_{B M}$ an free-morphemic $\sqrt{ }$ grond receives support from their different behavior. Firstly, the pattern onder de grond is productive in the sense that any "noun" (i.e. $\mathrm{n}+$ root) that can represent the so-called Ground is possible in this configuration: onder de \{tafel, boom, modder, arm, ... \} (under the table/tree/mud/arm). Notice now that the pattern ondergronds is non-productive. Many roots are excluded in this configuration: *onder \{tafels, booms, modders, arms, ... \}. Secondly, the meaning of the pattern onder de grond is typically compositional (i.e., can be derived from its parts), while the meaning of patterns such as ondergronds is often not. As shown in (50), for example, ondergronds and binnenskamers can have a more figurative meaning, namely 'secretly.'

a. $\mathrm{Zij}$ moeten nog steeds ondergronds oppositie voeren tegen het they must PRT still underground resistance act against the bewind. regime 'Their resistance to the regime still has to work underground/secretly.'

b. Deze afspraak moet binnenskamers blijven. this agreement must indoors stay 'This agreement must remain secret.'

Having shown that there is support for the distinction between free-morphemic $\sqrt{ }$ grond, on the one hand, and bound-morphemic $\sqrt{ } \operatorname{grond}_{B M}$, on the other hand, I return to the question about the appearance of $-s$. In onder de $\operatorname{grond}\left(*_{-}-s\right),-s$ does not surface as a realization of $n$ because $\sqrt{ }$ grond, the host of affixal $n$, is a free root. In ondergronds, on the other hand, the root $\sqrt{ }$ grond $_{B M}$ raises to $n$, yielding an amalgam

\footnotetext{
${ }^{38}$ As will be shown soon, patterns such as binnensmonds $\left(49 \mathrm{c} / \mathrm{c}^{\prime}\right)$ turn out to have a more complex structure.
} 
whose components are bound elements: $\left[\sqrt{ } \operatorname{grond}_{B M}+n_{\text {aff }}\right]$. It is in this exocentric head-head configuration that the two components must surface together at PF. Their mutual dependence requires the two elements to materialize together, yielding a single lexical unit at the surface: gronds.

Having provided an analysis of the pattern ondergronds, I would like to discuss two other phenomena relating to this construction, namely (i) the appearance of a proleptic $-s$ in expressions such as binnensmonds (see (42c)), and (ii) the appearance of ondergronds as an attributive adjectival modifier, as in een ondergrondse kamer (an underground-s-INFL room, 'a subterranean room'). I'll start my discussion with proleptic $-s$.

\subsubsection{Proleptic -s}

The attentive reader will have noticed that in expressions such as binnensmonds (42c), binnenskamers (43a), binnenshuis (43b) and buitenshuis (45c), there is an -s interspersed between the preposition and noun $+s$. Traditionally, this interspersed $-s$ has been characterized as 'proleptic $-s$ ', since it anticipates the occurrence of the final $-s$, as in binnensmonds. Since $-s$ typically surfaces in nominal environments, one would expect there be some nominal element present. In order to find this nominal element, we need to look into the "preposition." Given the fact that proleptic $-s$ is absent in expressions such as onder $\left(*_{-s}\right)$ gronds (42a) and bij(*-s)tijds (42b), it does not seem implausible to assume that there is some kind of nominal element present within "prepositions" such as binnen, boven, and buiten. This obviously implies that these apparent prepositions have a composite structure. I propose that they can be decomposed into three parts (see also Royen 1947-1954:115 and Aboh 2010 for Dutch, and Pretorius 2017 for Afrikaans).

$$
\begin{aligned}
& \text { a. } \text { binnen }=\text { be- }+ \text { in }+ \text {-en } \\
& \text { ('inside') }
\end{aligned}
$$
b. $\quad$ buiten $=$ be- + uit + -en ('outside')

The element be- has a prepositional flavor in the sense that it designates spatial information (specifically, location). This is clear, for example, from the slightly archaic patterns in (52), where be- means 'on/at': ${ }^{39}$
a. benoorden / bezuiden / bewesten / beoosten Amsterdam be-north-en / be-south-en / be-west-en / be-east-en Amsterdam 'on the north/south/west/east side of Amsterdam'
b. bezijden de waarheid
be-side-en the truth
'aside of the truth/not true'

Presumably, the P-like element be- in (52) is the same element as in (53b), where beis a prefix on the verb laden and alternates with the locative preposition op in (53a). Following Hoekstra (1988), I take be- to be an affixal preposition designating Place, which has been incorporated into the verb (laadde).

\footnotetext{
${ }^{39}$ See also English besides, beneath, and below. The element be 'by' has a locative meaning.
} 

a. Jan laadde hooi op de wagen. Jan loaded hay onto the wagon
b. Jan $b e_{i}+$ laadde [PP $t_{i}$ de wagen] met hooi. Jan PREF-loaded the wagon with hay 'Jan loaded hay onto the wagon.'

Let us next turn to the other two components in (51): -in/-uit/-ov and -en. I propose that -in/-uit/-ov are roots having a spatial meaning. ${ }^{40} \mathrm{I}$ assume that the element -en is the same element as in namens (name-en-s, 'on behalf of'); see Sect. 4.2. This means that $-e n$ is a "low" classifier-like element that heads the projection LexP, which is located in between the root and the categorial projection nP. Schematically:

$$
\text { [nP } \mathrm{n}[\text { LexP -en [ } \text { in }]]]
$$

Head movement of $\sqrt{ }$ in and adjunction to - en yields the amalgam [ $\sqrt{ }$ in+-en]. Recall from Sect. 4.2 that -en's function was to turn a root into a unit. Taking this perspective, the amalgams -innen, -uiten, and -oven are complex heads carrying the meaning 'inner side,' 'outer side,' and 'upper side,' respectively. As is clear from their meaning description, these nouns designate an axial part of an object, such as the (inner/outer) side or top of that object (Jackendoff 1996:14). Importantly, forms such as -innen do not occur as independent nouns; they must co-occur with the affixal preposition be-. In what follows, I will show how the bound-morphemic preposition be- and the bound-morphemic amalgam -innen "come together" and form the unit binnen (be+innen). Furthermore, I will provide an account of the double appearance of adverbial $-s$ in a linguistic expression like binnensmonds.

Starting point of my analysis is Svenonius's (2006) proposal that certain adpositional projections contain a functional layer designating an axial part of an object, e.g., its top, front, or sides. Svenonius, for example, proposes that the English adpositional expression inside of the house has the structure in (55), where in designates the location, side the axial part, and (of) the house the so-called GROUND.

$$
\text { [PlaceP [Place in] [AxPartP [AxPart side] [KP [K of] [DP the house]]]] }
$$

Building on this structural analysis, I propose that an expression like binnensmonds starts out from the base structure in (56), which has the possessive meaning 'in mouth's inner-side':

$$
\begin{aligned}
& \text { [PlaceP be- [AxPartP Spec [AxPart' AxPart [PosP [nP monds] [Pos' Pos [nP n [LexP } \\
& \text {-en [ } \sqrt{ } \text { in] }]]]]]]]
\end{aligned}
$$

According to this analysis, a possessive relationship is encoded in the lower part of the structure. The lower nP (complement of Pos) represents the possessum ('inner side'), the higher $\mathrm{nP}$ in [Spec,PosP] the possessor. In informal terms, the possessive relationship can be paraphrased as 'mouth's inner side.'

Let us next consider the derivation of the surface pattern binnensmonds, starting with the possessum -innens. I propose that innens has exactly the same derivation as namens ('on behalf of') in Sect. 4.2. This means the following: the root in in (56)

${ }^{40}$ See Wood and Marantz (2017) for discussion of prepositional roots. 
raises to -en, yielding the amalgam $[[\sqrt{ } / i n]-e n]$, which behaves like a bound form in the sense that it cannot occur on its own. Raising of the amalgam $[[\sqrt{ }$ in $]-e n]$ to the categorial head $n$ yields the complex head $[[\sqrt{ } i n]-e n]+n(=-s)]$. With both innen and $n$ being bound elements, we end up with an exocentric head-head configuration, the subparts of which share the property of being bound forms. I propose that in a configuration like this, the two heads must externalize jointly at PF. For $n$ this means that it spells out as $-s$, a last resort operation.

Let's next turn to the possessor monds in (56). I assume that monds has the same derivation as gronds (ground-s) in linguistic expressions such as bovengronds (aboveground-s); see $\left(49 \mathrm{a}^{\prime}\right)$. This means that mond is a bound root, that is: $\sqrt{ }$ mond $d_{B M}$. This bound-morphemic root raises to $n$, yielding an amalgam whose components are bound elements: $\left[\sqrt{ }\right.$ mond $\left.d_{B M}+n_{a f f}\right]$. Their mutual dependence requires the two elements to materialize together at PF, yielding a single lexical unit at the surface: monds.

Having accounted for the formation of the nPs innens and monds, let us finally consider the derivation of the word order pattern. Taking (56) to be the base structure, I assume that the nP innens undergoes phrasal movement from the complement position of Pos to the Specifier position of AxPart, located in the adpositional "middle field." This movement step, depicted in (57), yields the syntactic structure that surfaces as binnensmonds (i.e., be-[innens]-monds).

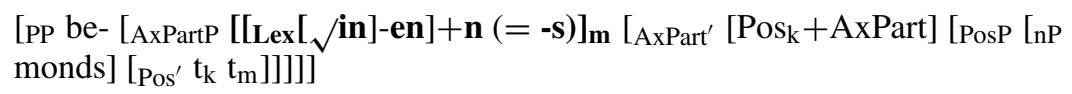

It should be noted that the nP innen crosses another $\mathrm{nP}$ on its way to [Spec,AxPartP], namely monds in [Spec,PosP]. This looks like a violation of locality (Rizzi's (1990) Relativized Minimality or Chomsky's (1995) Minimal Link Condition); the $\mathrm{nP}$ monds is closer to [Spec,AxPartP] than is the $\mathrm{nP}$ innen, and should therefore be the target of movement. However, following Chomsky's (1993) locality theory in terms of equidistance, the $\mathrm{nP}$ innen may cross the higher $\mathrm{nP}$ monds as long as the two nPs are equally far away from innen's extraction site. Under Chomsky's assumptions, this situation is obtained by the application of domain-extending head movement, in casu Pos-to-AxPart, as represented in (57). This operation creates a minimal domain containing both the moved $\mathrm{nP}$ innen and the possessor-nP monds.

\subsubsection{Ondergronds and binnensmonds as attributive adjectival modifiers}

So far, I have given evidence in support of the PP-like status of linguistic expressions such as ondergronds and binnensmonds; see (42). It should be pointed out, however, that these same expressions - at least, superficially the same-also display adjectival behavior. For example, they can be used as attributive adjectival modifiers, as shown in (58). Their adjectival nature is clear from the fact that they carry attributiveadjectival inflection $(-e)$, and occur in prenominal position, the characteristic position of attributive adjectives; compare with (47), where binnensmonds and binnenskamers are postnominal and lack an adjectival inflection.

$$
\begin{aligned}
& \text { a. [DP Dat BINNENSmondse gemompel] stoort mij enorm. } \\
& \text { that inside-mouth-s-INFL murmuring annoys me enormously } \\
& \text { 'That inarticulate murmuring annoys me enormously.' }
\end{aligned}
$$


b. [DP Een BIJtijdse afhandeling van deze vijf wetsvoorstellen] is a in-time-s-INFL completion of these five legislative-proposals is gewenst.

preferred

'A prompt completion of these five legislative proposals is hoped for.'

Further support for their adjectival (rather than prepositional) status comes from the fact that modifiers that typically occur inside PPs—-see (45)—are impossible with these prenominal expressions.
a. [DP een [(*ruim) bijtijdse $]$ afhandeling van deze vijf an amply in-time-s-INFL completion of these five wetsvoorstellen] legislative-proposals
b. [DP een [(*enkele meters) ondergrondse] grafkamer] a some meters under-ground-s-INFL tomb

Notice, finally, that an attributive modifier like bijtijds in (58b) can combine with the degree word zeer, and even display bound comparative morphology (-er), which are both clear signs of adjectival behavior.
a. Deze zeer bijtijdse
aankondiging was door iedereen vergeten. this very in-time-s-INFL announcement was by everyone forgotten
b. Bijtijdser kan je niet zijn!
in-time-s-COMPAR can you not be
'You can't be more modern than this!'

The question, obviously, arises how to analyze these adposition-like expressions that display adjectival behavior. One option would be to say that there is an adjectival categorizer $a$ that selects a PP, as in (61).

$$
\text { [aP a [PP onder }[\mathrm{nP} \mathrm{n}(=-s)[\sqrt{ } \text { grond }]]]
$$

A potential problem for this analysis could be the fact that PP-modifiers are blocked, as in (59). One might argue, however, that there is a general ban on adjectivizing a (truly) phrasal structure; ${ }^{41}$ that is, onder+gronds can only become an adjective, if there is a sequence of successive head movement steps- $\mathrm{R}(\mathrm{oot})$ to $n ;[\mathrm{R}+\mathrm{n}]$ to $\mathrm{P}$; $[\mathrm{P}+[\mathrm{R}+\mathrm{n}]]$ to $a$-that ultimately yields the complex amalgam $[[$ onder-grond $-s]+a]$.

A problem for this analysis, however, are patterns such as binnensmonds(-e) in (58a). If this attributive modifier has the structure $\left[\begin{array}{l}a P \\ a\end{array}\right.$ [PP binnensmonds]], where binnensmonds has the inner organization in (57), then it is impossible to derive a complex (adjectival) head [[binnensmonds] $+a]$ by means of a sequence of successive head movement steps. There is no way to head-move honds in [Spec,PosP] to binnens. Furthermore, the sequence be- + innens does not form a complex head in (57).

An alternative analysis for adjectival modifiers such as ondergronds and binnensmonds would be to say that their adjectival behavior is due to the fact that grond

\footnotetext{
${ }^{41}$ I would like to thank a reviewer for this suggestion.
} 
(ground), mond (mouth) et cetera are roots that can be turned into an adjective by combining with the categorizing head $a$, as in (62). Importantly, and as will be discussed more elaborately in Sect. 6, this categorizing head can be realized as $-s$, just like $n$.

$$
\text { [PP onder }[\mathrm{aP} \text { a }(=-s)[\sqrt{ } \text { grond }]]]
$$

The adjectival behavior of root $+-s$ amalgams is more common, as is clear from examples such as een zomer-s-e dag (a summer-s-INFL day, 'a summery day'), zijn slaafse gedrag (his slave-s-INFL behavior, 'his slavish behavior,' and een Deense taalkundige (a Dane-s-INFL linguist, 'A Danish linguist'). A question triggered by the analysis in (62), however, concerns the fact that an adposition takes an adjectival phrase (aP) as its complement. In general, adpositions typically combine with noun phrases, and not with adjectival phrases. It should be noted, though, that patterns can be found in Dutch, where an attributive adjective follows an adposition, as in een ver(re) van eenvoudige oplossing (a far from simple solution); see van Riemsdijk (2001). Importantly, this pattern features a modifier (ver $(r e))$ before the adposition van. As was shown in (59), such modifiers are impossible in patterns such as ondergronds, which suggests that patterns such as ondergronds $(-e)$ should be distinguished from the pattern verre van eenvoudig(-e). Notice that, also for the analysis in (62), it is not entirely clear why modification of the adpositional phrase is blocked.

I finish this section with a third, quite tentative proposal regarding adjectival patterns such as ondergronds and binnensmonds. Suppose these attributive modifiers do not represent a $\mathrm{P}+$ complement structure but instead constitute exocentric phrasal structures in which onder and binnens act as phrasal modifiers adjoined to an attributive aP, which itself acts as an attributive modifier in (58) and (59).

$$
\begin{array}{ll}
\text { a. } & {[[\mathrm{PP} \text { onder }][\mathrm{aP} \mathrm{a}(=-s)[\sqrt{ } \text { grond }]]]} \\
\text { b. } & {[[\mathrm{PlaceP} \text { be- }[\mathrm{nP} \mathrm{n}(=-\mathrm{s})[\mathrm{LexP}-\mathrm{en}[\sqrt{ } \text { in }]]]]+[\mathrm{aP} \text { a }(=-s)[\sqrt{ } \text { mond }]]]}
\end{array}
$$

I assume that gronds and monds constitute $\operatorname{Root}_{\mathrm{BM}}+a$ amalgams that express a relational meaning. They do not denote a property of the noun they modify, as oude 'old' does in een oude grafkamer 'an old tomb,' but express a relation between two entities. In een ondergrondse grafkamer in (59b), this relation is between grafkamer (the modifiee) and gronds (the modifier), and in dat binnensmondse gemompel in (58a) between gemompel (the modifiee) and monds (the modifier). It is the spatial modifier (onder and binnens) adjoined to aP that specifies the nature of the relationship, viz., a spatial relationship. It does not seem unlikely that we have the same structure in Dutch expressions such as extra-parlementair 'extra-parliamentary, outside of parliament' and intra-musculair 'intra-muscular, inside of muscles,' which feature the Latin-based elements extra 'outside' and intra 'inside,' which have spatial meaning. I will leave an in-depth analysis of the patterns in (58) for future research.

\section{Adverbial -s: A cross-adverbial phenomenon}

So far, I have presented three case studies on adverbial $-s$, which I analyzed as a manifestation of $n$. It was proposed that this categorizing node surfaces as $-s$ in three 
structural configurations: In the pattern zachtjes (3.1), $n$ forms an amalgam with the silent root $W A Y$ and surfaces as $-s:[\sqrt{ } W A Y+n(=-s)]$. In the pattern namens (3.2), $n$ forms an amalgam with the complex head [[ $\sqrt{ } n a(a) m]-e n]$, which features the "low" affix -en and constitutes a bound form that cannot occur on its own. In ondergronds, $n$ forms an amalgam with a bound root: $\left[\sqrt{ }\right.$ grond $\left._{B M}+n(=-s)\right](4.3 .1)$. The purpose of Sect. 5 is to show that adverbial $-s$, hidden though it may be, is a quite common phenomenon in Dutch morphosyntax, and that the structural configurations discussed in Sect. 3 are also attested in other types of nominal expressions featuring adverbial $-S$.

\subsection{Temporal expressions with adverbial -s}

Dutch has quite a number of temporal adverbs featuring adverbial $-s$ at the end, such as eens (one-s 'once/one time'), opeens (at-one-s 'at once'), ineens (in-one-s 'at once'), soms (some-s 'sometimes'), and straks (soon-s 'soon'). There are also temporal expressions that have a proleptic adverbial $-s$ at the beginning of the temporal expression besides having one at the end, as in 's avonds (-s-evening-s 'in the evening'), 's ochtends (-s-morning-s 'in the morning'), 's nachts (-s-night-s 'at night') and 's middags (-s-afternoon-s 'in the afternoon'). ${ }^{42}$

Let's start our discussion with the patterns eens and op/in+eens, in which adverbial $-s$ is attached to the numeral een 'one' (pronounced /e:n/). In op/in+eens, a preposition precedes the sequence een+-s. Phonological stress does not fall on the preposition but on the numeral: inEENS, opEENS. This stress pattern hints at the presence of a phrasal structure rather than a complex word structure, specifically, a prepositional structure: $[P P$ in/op $[X P$ eens $]] .{ }^{43}$ The fact that these adverbs can be paraphrased by phrases featuring an overt noun designating (a point in) time-namely the noun keer 'time' - hints at the presence of syntactic structure: in één keer (in one time, 'at once'), op 'n keer (at a time, 'once'). Importantly, when the noun keer is present, $-s$ cannot appear: in een $\left(*_{-s}\right) \operatorname{keer}\left(*_{-s}\right)$. I interpret the contrast between ineen $*(-s)$ and in een $\left(*_{-s}\right)$ keer $\left(*_{-s}\right)$ as follows: in the former pattern, the categorial head $n$ combines with a silent root (TIME), as in (64). ${ }^{44}$ I assume that in this complex head configuration featuring a silent root-that is, $[\sqrt{ } T I M E+n]$ - the categorizing head $n$ externalizes as a last resort. Since the root does not get spelled out, $n$ must surface overtly, the underlying assumption being that in a head-head amalgam at least one of the elements must externalize.

$$
\text { [PP in/op [NumP een }[\mathrm{nP}[\sqrt{ } \text { TIME }+\mathrm{n}(=-s)][\sqrt{ } \text { TMME }]]]]
$$

When the root is overt, as in in één keer (in one time, 'at once') we have the amalgam $[\sqrt{ }$ keer $+n]$, with $n$ adjoined to a free root (in line with Chomsky 2015). With affixal

\footnotetext{
${ }^{42}$ This pattern is quite productive. It also occurs with days of the week (e.g., 's Maandags 'on Monday'; 's Woensdags 'on Wednesday') and the seasons of the year (e.g., 's Winters 'in Winter'; 's Zomers 'in Summer').

${ }^{43}$ Composite words display stress on the first element, as in INkeer, lit.: in-turn 'repentance', and opmaat, lit.: up-measure 'upbeat').

${ }^{44}$ Compare with the manner adverb zachtjes in Sect. 3.1, which featured the silent root WAY.
} 
$n$ being embedded in the complex root, $n$ is invisible from the outside. I assume that, in this head-head configuration, $n$ does not surface (i.e., externalize) as $-s$.

The analysis of eens in (64) extends to the preposition-less pattern eens (one$\mathrm{s}$, 'once/one time'). Thus, it has the following structure: $[$ NumP een $[\sqrt{ }$ TIME $+n(=$ $\left.\left.-s)]\left[\sqrt{ }^{\mathrm{THME}}\right]\right]\right]$. Interestingly, besides the phonologically strong form eens (/e:ns/), Dutch has the weak adverbs ' $n s$ (/əns/) and 's (/əs/), which carry the same meaning: 'once/one time.' I assume that the sequence 'ns has a composite structure consisting of the elements -en (i.e, /on/) and $-s$. I propose that / $/ 2 n /$ is the classifying derivational morpheme that was identified in expressions such as namens ('on behalf of') and binnensmonds ('inarticulately'). This means that the temporal adverb ' $n s$ has the following base structure, where -en instantiates the Lex-head: ${ }_{n} P n(=-s)[$ LexP $-e n$ $[\sqrt{ }$ TIME $]]$. The form ' $n s$ is derived by raising the silent root to Lex, and subsequently raising the amalgam $[\sqrt{ }$ TIME $+-e n]$ to $n$, which spells out as $-s$ because of the bound status of $[\sqrt{ } T I M E+-e n]$; that is, the latter element cannot occur on its own. As for the temporal adverb 's, I assume it lacks the LexP-layer and has the following derived structure: $[n P[n \sqrt{ } T I M E+n(=-s)][\sqrt{ } T I M E]] .{ }^{45}$ As we will see below, this small temporal $n$ also occurs in temporal expressions featuring proleptic $-s$.

The approach taken so far can be extended to temporal adverbs such as soms 'sometimes' and straks 'soon'. I propose that they both have a composite structure featuring a silent root designating 'time.' Soms has the structure in (65a), with som realizing the Num-head, while straks has the structure in (65b), with strak being an adjectival modifier of the silent temporal $\mathrm{nP}^{46}$

$$
\begin{array}{ll}
\text { a. } & {[\text { NumP som }[\mathrm{nP}[\sqrt{ } \text { TIME }+\mathrm{n}(=-s)][\sqrt{ } \text { TIME }]]]} \\
\text { b. } & {[\text { FP strak }[\mathrm{F}, \mathrm{F}[\mathrm{nP}[\sqrt{ } \text { TIME }+\mathrm{n}(=-s)][\sqrt{ } \text { TIME }]]]]}
\end{array}
$$

Let's, finally, consider temporal expressions such as 's avonds (-s-evening-s, 'in the evening'), which display an adverbial $-s$ both at the beginning-so-called proleptic $-s$-and at the end of the temporal expression. Historically, the initial $-s$ is a reduced form of the element des, which can still be found in archaic temporal expressions such as des zomers (the-GEN summer-GEN 'in the summer'); see Royen (1947-1954:354363). As we saw earlier, the reduced $-s$ is also found in the temporal expression ' $s$ 'once, one time', which was analyzed as $\left[n P[n \sqrt{ } T I M E+n(=-s)]\left[\sqrt{ }^{T I M E}\right]\right]$. I propose that the initial $-s$ that we find in 's avonds (and similar expressions) is the same element and, consequently, has the same structure. According to this analysis, 's avonds corresponds to $\left[[\sqrt{ } T I M E+n(=-s)]\left[\mathbb{V}^{T I M E}\right]\right]+$ avonds, that is, 'evening's time.' In other words, these adverbial expressions have a meaning that is reminiscent of possessive noun phrases such as Jans huis 'Jan's house'. There is an important word order difference, though; in Jans huis, the possessor precedes the possessum, whereas in $[\sqrt{ }$ TIME $+n(=-s)][\sqrt{ }$ TIME $]]+$ avonds, the possessor (avonds) follows the posses$\operatorname{sum}([\sqrt{ } \operatorname{TIME}+n(=-s)])$. The latter word order is, of course, familiar from so-called

\footnotetext{
${ }^{45}$ The weak forms 'ns and 's are impossible in combination with op/in: *op/in'ns and *op/in's. At the moment I have no explanation for this. Note that $\mathrm{P}$ can combine with a weak personal pronoun, as in op/in 'm ('on/in him').

${ }^{46}$ In Standard Dutch, som is found in combination with the suffix -ig, as in sommige mensen, some+ig+INFL persons, 'some people'). Certain Dutch dialects use som in those contexts, as in Kempenland Dutch som minse 'some people' and som joore 'some years'; see De Bont (1958).
} 
Construct State (CS) possessive noun phrases. In line with my analysis of namens (name $+e n+s$, 'on behalf of') in Sect. 4.2., I take the word order 'possessum + possessor' to result from phrasal movement of the possessum to the edge (i.e., specifier) of DP. The possessum surfaces in a minimal way, namely as $-s$, which I take to be a realization of $n$. The possessor, on the contrary, features an overt root carrying $-s$ : $[\mathrm{nP} \sqrt{ }$ ochtend $+\mathrm{n}(=-s)[\sqrt{ }$ ochtend $]]{ }^{47}$

$$
\left.\left.\left.\left[\mathrm{DP}[\sqrt{ } T I M E+n(=-s)]\left[\sqrt{ }^{\text {TIMEE }}\right]\right]_{\mathrm{k}}\left[\mathrm{D} \text { ' D [PosP ochtends [Pos' Pos } \mathrm{t}_{\mathrm{k}}\right]\right]\right]\right]
$$

Evidence in support of the displacement analysis in (66) comes from the temporal expressions in (67), where the adjectival modifiers vroeg 'early' and laat 'late' follow 's ochtends.

['s Ochtends vroeg] / ['s Avonds laat] vertrekken we. -s morning-s early / -s evening-s late leave we 'We will leave early in the morning/late in the evening.'

Under a CS-analysis, this special placement of the adjectival modifier follows directly. The adjective is an attributive modifier that modifies the $\mathrm{nP}[[\sqrt{ } T I M E+n(=-s)]$ $[\sqrt{ }$ TIME $]$. The meaning of the temporal expressions in (67) corresponds to 'morning's early time'/'evening's late time.' The nP raises to [Spec,DP] and crosses both the attributive adjective (laat/vroeg) and the possessor (ochtends/avonds), as represented in (68):

$\left[\mathrm{DP}\left[\mathrm{nP}[\mathrm{n} \sqrt{ } \mathrm{TIME}+\mathrm{n}(=-\mathrm{s})] \sqrt{ } \mathrm{TIME}_{\mathrm{k}}[\right.\right.$ PosP ochtends [Pos, Pos [FP vroeg $[\mathrm{F}$, $\left.\left.\left.\left.\left.\mathrm{F} \mathrm{t}_{\mathrm{k}}\right]\right]\right]\right]\right]$

Summarizing, I proposed in this section that the adverbial $-s$, as present in temporal adverbial expressions, is a manifestation of the categorizing node $n$, which takes $[\sqrt{ }$ TIME $]$ or $[$ LexP $-e n[\sqrt{ }$ TIME $]]$ as its complement. The categorizing head $n$ externalizes as a last resort operation. ${ }^{48}$

\subsection{The measure expression ietsje(s)}

This section discusses the (optional) appearance of adverbial $-s$ on the measure phrase ietsje(s), which can be decomposed into three parts: the element iets 'somewhat,' the

\footnotetext{
${ }^{47}$ Compare gronds in bovengronds in Sect. 4.3.1.

${ }^{48} \mathrm{In} \mathrm{fn.} \mathrm{22,} \mathrm{I} \mathrm{noted} \mathrm{that,} \mathrm{in} \mathrm{this} \mathrm{article,} \mathrm{I} \mathrm{would} \mathrm{not} \mathrm{address} \mathrm{the} \mathrm{question} \mathrm{as} \mathrm{to} \mathrm{whether} \mathrm{expressions} \mathrm{featuring}$ adverbial $-s$ are embedded within a PP headed by a silent P. It was shown that the manner expression zachtjes could not be extraposed, suggesting that it is a nominal expression, while a temporal expression like die dag 'that day' could be extraposed, suggesting that the latter is a PP. Notice that, superficially, P-less temporal expression such as soms, strakjes, and 's avonds can occur in extraposed (= postverbal) position; see (i). This suggests that these temporal expressions featuring $-s$ are embedded within a PP. I leave a systematic study of this issue for future investigation.
}

$$
\begin{aligned}
& \text {... dat Jan <soms/strakjes/'s avonds }>\text { naar de sauna gaat <soms/strakjes/'s avonds }>\text {. } \\
& \text { that Jan sometimes/soon/in-the-evening to the sauna goes } \\
& \text { '... that Jan will go to the sauna sometimes/soon/in the evening.' }
\end{aligned}
$$


diminutive morpheme $-j e$, and the (optional) $-s$. The phenomenon is exemplified in (69): ${ }^{49}$
a. Deze twee kazen verschillen iets-je(-s)
van smaak. these two cheeses differ somewhat-DIM(-s) of taste 'These two pieces of cheese have a slightly different taste.'
b. Jan arriveerde iets-je(-s) te laat.
Jan arrived somewhat-DIM(-s) too late
'Jan arrived somewhat too late.'

In order to come to an analysis of the pattern ietsjes, we need to examine more carefully the individual components of ietsje $(s) .{ }^{50}$ As a first step, I make a brief remark about the historical origin of iets, because it can help us in discovering its inner structure in present-day Dutch. Historically, iets derives from the sequence ie- ('ever/sometime') + wicht ('thing') + wes ('what ${ }_{\mathrm{GENITIVE}}$ '); see Van der Sijs (2010). ${ }^{51}$ The sequence ie-wicht got reduced to the form iet, and wes to the form $-s$, together yielding iets. ${ }^{52}$ I assume that, in present-day Dutch, iets still has a composite structure: iet+-s. I take the component iet to be a bound root carrying the meaning 'thing.' In present-day Dutch, this bare form iet does not occur as a free morpheme but is still found in certain fixed expressions, as, for example, in the fixed coordinate pattern iet of wat (something or what, 'somewhat, a bit'). ${ }^{53}$

I propose that the bound root $\sqrt{ }$ iet raises to $n$, yielding the amalgam $[\sqrt{ }$ iet $+n]$, as depicted in (70): ${ }^{54}$

$$
[\mathrm{nP}[\sqrt{ } \text { iet }+\mathrm{n}(=-\mathrm{s})][\sqrt{ } \text { iet }]
$$

${ }^{49}$ Iets can also have a referential reading, that is 'something,' as in Jan vergat iets (Jan forgot something). Interestingly, this referential iets cannot combine with a diminutive morpheme: Jan vergat iets $\left({ }^{*} j e\right)$; 'Jan forgot something (small).' I tentatively propose that the referential reading of iets is obtained by moving it into [Spec,DP]; compare with (71b), where movement of iets to [Spec,QP] yields the quantificational/measure reading 'somewhat.'

${ }^{50} \mathrm{Next}$ to the measure expressions iets and ietsje(s) Dutch has the patterns ietswat and wat, which also have the meaning 'somewhat.' I leave the analysis of these patterns for future research, but would like to point out that wat, as opposed to iets, cannot combine with the diminutive -je: *wat-je (intended meaning: 'somewhat'). Possibly, the non-co-occurrence of wat and -je is due to the fact that they compete for the same syntactic position, namely Q(uantifier). The quantifier-like status of wat is clear from its appearance in noun phrases such as wat boeken (what books, 'some books').

${ }^{51}$ Note that, in the [+HUMAN] indefinite pronoun iemand 'someone', the counterpart of wicht 'thing' is still identifiable: ie-man-d (ie + 'man' + paragogic /t/, 'someone').

${ }^{52}$ The sequence iet+wes is still visible in the German form etwas ('something, somewhat').

${ }^{53}$ In certain present-day Dutch dialects, the $-s$-less form iet is still used as a free morpheme (Corver et al. 2011).

${ }^{54}$ As a reviewer points out, the nominal status of iets is also supported by the contrast between Dutch niets and niet. The former means 'nothing' and is the negative counterpart of iets 'something,' the latter is the negative word (meaning 'not') that is used for expressing sentential negation or constituent negation. I assume that niet is a functional category (say, a Neg-head) with a non-composite form, which means that the nominal component iet is not present in niet. Notice at this point that iet does not function as the (emphatic) affirmative counterpart of niet. For this, Dutch uses the word wel (emphatic affirmation). The element niets 'nothing,' on the contrary, does have a composite structure: $n$-iet-s, where the subpart iets has the structure in (70). I tentatively propose that the negative component $n$ - in niets occupies the Q-head that selects $\mathrm{nP}$. So we have the following structure: $[Q P n-[\sqrt{ } \boldsymbol{i e t}+n(=-s)] \sqrt{ }$ iet $]]$. Potential support for 
The components of this amalgam have an equal status in the sense that they are both bound morphemic (BM) elements. I assume that in this exocentric head-head configuration- $\left[\sqrt{B M}_{B M}+n_{\text {affixal }}\right]$ - the two components externalize jointly at PF. Their mutual dependence-both being bound elements - requires that the two elements materialize together, yielding a single lexical unit at the surface. I take externalization of $n$ as $-s$ to be a last resort operation: $-s$-support must take place in order to externalize the exocentric complex head.

Having provided an analysis of iets, let's next examine the alloforms ietsje $(s)$ in (69). Following my analysis of diminutive -je in zachtjes (silent/soft-DIM-s, 'silently/softly'), as given in Sect. 4.1, I propose that -je is located in Q. With -je occupying Q, we end up with the base structure in (71a) for ietsje. I propose that the sequence ietsje is derived in two steps: (i) head movement of $\sqrt{\text { iet }}$ to $n$, as in (71a), followed by (ii) nP-movement to Spec,QP. The derived structure is given in (71b), where only the second movement step has been represented.

$$
\begin{aligned}
& \text { a. } \quad\left[\mathrm{QP} \text { Spec }\left[\mathrm{Q}^{\prime} \text {-je }[\sqrt{ } \text { iet }+\mathbf{n}(=-\mathrm{s})] \sqrt{ } \text { iet }\right]\right] \text { step } 1 \\
& \text { b. } \quad\left[\mathrm{QP}[\sqrt{ } \text { iet }+\mathbf{n}(=-\mathrm{s})]\left[\mathrm{Q}^{\prime}-\mathrm{je}[\sqrt{ } \text { iet }+\mathbf{n}(=-\mathrm{s})]\right]\right] \text { step } 2
\end{aligned}
$$

Let's now turn to ietsjes, which displays an adverbial $-s$ at the end of the string. I propose that ietsje and ietsjes differ from each other only in the richness of Spellout of the movement chain. In ietsje (71), $n$ materializes only within the head of the $\mathrm{nP}$-movement chain, that is within the $\mathrm{nP}$ occupying [Spec, $\mathrm{QP}]$. In ietsjes, on the contrary, $n$ materializes both within the head of the nP-chain and within the foot of the $\mathrm{nP}$-chain. This is depicted in (72), which is derivationally preceded by (71a): ${ }^{55}$

$$
\left[\mathrm{QP}[\sqrt{ } \text { iet }+\mathbf{n}(=-\mathbf{s})]\left[\mathrm{Q}^{\prime}-\mathrm{je}[\sqrt{ } \text { iet }+\mathrm{n}(=-\mathrm{s})]\right]\right]
$$

The question, of course, arises as to why the categorizing head (optionally) surfaces twice in (72). Possibly, ietsjes is a slightly more emphatic variant of ietsje.

Summarizing, I proposed in this section that the measure expression ietsjes is a linguistic expression with a composite structure. Both the interspersed $-s$ and the final $-s$ are manifestations of the categorizing node $n$. The presence of interspersed $-s$ is induced by the bound-morphemic nature of the root iet. The final (optional) $-s$, was

this analysis comes from the complementary distribution of diminutive -je, which I take to be in Q, and negative $n$-, as exemplified in (i):

$$
\begin{aligned}
& \text { Ik vind hem iets(-je) / niets }\left(*_{-j e}\right. \text { je te lang. } \\
& \text { I consider him somewhat(-DIM)/ nothing(-DIM) too tall } \\
& \text { 'I think he is somewhat too tall/in no way too tall.' }
\end{aligned}
$$

\footnotetext{
${ }^{55}$ For multiple spell out of chain positions, see, among others, Nunes (2004). The multiple Spell-out approach in (72) could possibly be extended to partitive-genitival constructions of the type iets (erg) moois (something-s very beautiful-s, 'something (very) beautiful'), where the adjective is followed by $-s$. Rather than interpreting $-s$ as being part of the adjective, one might analyze it as a minimal spell-out of the nP-copy, as depicted in (i). In (i), the nP iets raises across the attributive AP to [Spec,DP], the locus of referential information.
}

(i) $\quad\left[\mathrm{DP}\left[\mathrm{nP} \sqrt{ } \text { iet }_{\mathrm{i}}+\mathrm{n}(=-\mathrm{s}) \mathrm{t}_{\mathrm{i}}\right]_{\mathrm{k}}\left[[\mathrm{AP}\right.\right.$ mooi $\left.\left.]\left[\mathrm{t}_{\mathrm{k}}(=-\mathrm{s})\right]\right]\right] \quad\left(\right.$ where $_{\mathrm{k}}=[\sqrt{\text { iet }+\mathrm{n}(=\mathrm{s})])}$ 
analyzed as a manifestation of the trace/copy-specifically, its $n$-component-left behind after nP-movement.

\subsection{The degree expression vliegens}

This section examines the occurrence of adverbial $-s$ in structural contexts like (73):
a. Jan verliet [vliegens vlug] de kamer.
Jan left fly-en-s fast the room
'Jan left the room in the blink of an eye.'
b. Het was er [stervens koud].
it was there die-en-s cold
'It was freezing cold out there.'

In each of the examples, we seem to have a verb-like element (e.g., vliegens) that acts as a degree modifier of a gradable adjective (e.g., vlug). ${ }^{56}$ An expression like vliegens vlug in (73a) has the paraphrase 'so fast that you are flying/fast as if you are flying.' This metaphorical reading corresponds to the degree reading 'very fast.' An important characteristic of the degree modifier is the presence of adverbial $-s$. This $-s$ is obligatory: *vliegen vlug. ${ }^{57}$

Before turning to an analysis of $-s$, I should point out that the sequences vliegens vlug and stervens koud are not compounds but phrasal constituents. Evidence for this comes from phonological stress. Under a neutral intonation, phonological stress falls on the second element, as is characteristic of phrasal stress. Thus, stervens KOUD, and not STERVENS koud. ${ }^{58}$ Importantly, stervens (and also vliegens) can become phonologically more prominent when they are used emphatically, which, obviously, is possible with degree modifiers. This emphatic reading of the degree modifier often leads to a stretched pronunciation in which each syllable receives its own stress: STÉR-VÉNS koud.

As shown in (74a), the degree modifiers in (73) cannot co-occur with adjectival degree modifiers such as erg 'very' and vreselijk 'extremely,' which suggests that

\footnotetext{
${ }^{56}$ Besides the degree adverbs in (73), in which $-s$ is attached to a verb-like element, Dutch has degree adverbs of the following type, in which adverbial $-s$ is attached to a noun-like element: honds brutaal (dog$\mathrm{s}$ impertinent 'very impertinent'), doods bang (dead-s afraid 'deadly afraid'), bliksems goed (lightning-s well 'damn/very well'). I will leave these patterns for future research. Analyzing these patterns along the lines of (onder)gronds ((under)ground-s) in Sect. 4.3.1 seems to be a plausible way to go.

${ }^{57}$ Certain Dutch dialects permit adverbial $-s$ on manner-adverbials. Example (i) illustrates this for Katwijk Dutch (Overdiep 1940). Present-day Standard Dutch uses a present participial form in those contexts: lopend. I assume that forms such as loopes in (i) receive the same analysis as vliegens en stervens in (73b); see below in the main text.
}

$$
\begin{aligned}
& \text { Gae je loopes? } \\
& \text { go you walk-s } \\
& \text { 'Will you go walking?' }
\end{aligned}
$$

${ }^{58}$ Examples of compounds, with phonological stress on the infinitival form, are the following: het STERVENSgevaar (the die-s-danger, 'the danger of dying'), de STERVENSduur (the die-s-duration, 'the length of the dying process'). Compare these forms with patterns featuring the degree element stervens: stervens GEVAARLIJK (die-s dangerous 'very dangerous'), and stervens DUUR (die-s fast 'very fast'). 
they compete for the same structural position. I take this position to be [Spec,QP] of the extended adjectival projection. As shown by (74b), vliegens can be preceded by the degree word zo 'so,' which I take to be the head of DegP, the layer on top of (adjectival) QP; see Corver 1997. ${ }^{59}$

a. Jan verliet $\left[\mathrm{QP}\left(* \mathrm{erg} / *^{*}\right.\right.$ vreselijk) vliegens $\left[\mathrm{Q}^{\prime} \mathrm{Q}^{\mathrm{O}}\right.$ [AP vlug]]] de kamer. Jan left very/extremely fly-en-s fast the room 'Jan left the room in the blink of an eye.'

b. ... [DegP Zo [QP vliegens [Q' $\mathrm{Q}^{\mathrm{O}}[\mathrm{AP}$ vlug $\left.\left.\left.]\right]\right]\right]$ de kamer dat ik hem so fly-en-s fast the room that I him niet herkende. not recognized '(Jan left) the room so fast that I didn't recognize him.'

Let's now address the question as to why adverbial $-s$ must appear in (73). For answering this question, we need to find out what the inner structure of vliegens is like. From a surface perspective, the subpart vliegen, to which adverbial $-s$ is attached, looks like an infinitival form. As shown in (75), the suffix -en occurs on infinitives, both in their verbal use and in their nominal use:
Jan gaat morgen weer vliegen, omdat hij vliegen leuk vindt. Jan goes tomorrow again fly because he fly nice considers 'Jan will fly again tomorrow, since he likes flying.'

As has been noted by traditional grammarians, however, forms like vliegens in (73) historically derive from present-participial forms (de Vooys 1967:257). In the case of vliegens, this is the form vliegend, which has -end as participial morphology. The final (dental) consonant of this participial morpheme disappeared, which led to the surface form vliegen.

Importantly, degree modifiers having an integral present-participial form -end are still possible in present-day Dutch. Some examples are given in (76). Note that the $-s$-variant is impossible here.
a. Jan verliet [tergend /*tergens langzaam] de kamer. Jan left agonizing slow the room 'Jan left the room agonizingly slowly.'
b. Het was er [gloeiend /*gloeiens heet]. it was there burning hot 'It was burning hot out there.'

Both the historical development of forms such as vliegens and the contrast between the examples in (73) and those in (76) suggest that the appearance of $-s$ correlates with the absence of integral participial morphology. Possibly, participial forms

\footnotetext{
${ }^{59}$ The -ens-forms discussed so far occupy a specifier position: (i) namens (name-en-s 'on behalf of'; Sect. 4.2) occupies [Spec,PP]; (ii) -innens, a subpart of binnensmonds (b-in-en-s-mouth-s 'inarticulately'; Sect. 4.3.2) occupies [Spec,AxP], and vliegens (fly-en-s 'very/extremely' (74)) occupies [Spec,QP]. The question arises as to whether there is a deeper property that underlies this generalization. I will leave this for future research.
} 
such as vliegend got reanalyzed along the following lines: The truly participial form $\left[\right.$ lieg $+\left[{ }_{\text {PRTC }}\right.$ end $\left.]\right]$ got reanalyzed as $[v$ lieg $]+-e n+-d$, where $-d$ (pronounced as a voiceless stop /t/) got interpreted as an expletive sound (so-called paragogic /t/). Due to its expletive nature, $-d$ ultimately disappeared. Suppose now that, within the remaining sequence [vlieg]+-en, the element -en is identical to the -en in expressions such as namens (name-en-s 'on behalf of'; Sect. 4.2) and binnensmonds (inside-smouth-s 'inarticulately'; Sect. 4.3.2). Under this analysis, -en is a derivational morpheme with a classifier-like function, more specifically a dividing function in the sense of Borer (2005). I assume it portions out the mass denoted by the root vlieg and turns it into a unit, say 'flying.' This unit is a degree unit, that is, a point on the scale of degrees. It represents a degree that equals 'flying.'

The derivational steps for vliegens are given in (77) and are similar to those for namens (see (39)) and (b)innens (see (57)):

$$
\begin{aligned}
& \text { a. } \quad[\mathrm{nP} \mathrm{n}[\text { LexP Lex }(=- \text { en })[\sqrt{ } \text { vlieg] }] \\
& \text { b. } \quad[\mathrm{nP} n[\text { LexP }[\text { Lex }[\sqrt{ } \text { vlieg]-en }], \sqrt{ } \text { vlieg }]] \\
& \text { c. } \quad\left[{ }_{n P}[[\text { Lex }[\sqrt{ } \text { vlieg }]-e n]+n(=-s)][\text { LexP } \text { Lex }[\sqrt{ } \text { vlieg }]-e n][\sqrt{ } \text { vlieg }]\right]
\end{aligned}
$$

(77a) represents the base structure. In (77b) the root vlieg raises to -en, yielding the bound amalgam $[$ Lex $[\sqrt{ }$ vlieg $]-e n]$. Raising of the amalgam $[$ Lex $[\sqrt{ }$ vlieg $]-e n]$ to the categorial head $n$ yields the complex head $[[$ Lex $[\sqrt{ }$ vlieg $]-e n]+n(=-s)]$ in $(77 \mathrm{c})$. With vliegen and $n$ both being bound elements, we end up with an exocentric head-head configuration, whose subparts are morphologically similar (i.e., bound-morphemic). In a configuration like this, the two heads externalize jointly at PF. Their mutual dependence_-both being bound elements_-requires the two elements to materialize together, yielding a single lexical unit at the surface.

\section{Adverbial -s as a manifestation of $a$}

In Sects. 4 and 5 we have come across various nominal expressions featuring socalled adverbial $-s$. It was proposed that $-s$ is a manifestation of the categorizing node $n$, and that it surfaces in specific structural configurations. In this section it will be shown that adverbial $-s$ also appears in adjectival expressions. I will propose that $-s$ can be a manifestation of the categorizing node $a .{ }^{60}$ Importantly, and maybe not

\footnotetext{
${ }^{60}$ I follow here Marantz $(1997,2000)$, who argues explicitly for the existence of the categorizing head $a$ next to $n$ and $v$; see also Lowenstamm (2014). Marantz claims that $a$ encodes a "property" at the interpretive level. See, however, Fábregas and Marín (2017), who point out that the property reading is not unique to the category 'adjective.' Certain nouns (e.g., hue) and verbs (e.g., to exist) also seem to denote properties. On the basis of this observation but also the argument that adjectives do not display the full range of behavioral properties attested for $n$ and $v$-e.g., the absence of light adjectives, periphrastic adjectives and semi-lexical adjectives-Mitrović and Panagiotidis (2020) propose that the categorizing head $a$ does not exist. According to them, the only categorizing heads are the nominalizer $n$ and the verbalizer $v$. What they call 'adjectives' are syntactically derived objects that take a two-layered structure consisting of an nP-layer and a higher vP-layer as their base. For reasons of space, I'll abstract away from an in-depth discussion of the important question as to whether $a$ exists as a separate categorizing head or whether it can be reduced to the categorizing heads $n$ and $v$. The grammatical behavior of complex patterns such as ondergronds (Sect. 4.3.1) and binnensmonds (Sect. 4.3.3), which can act both as postnominal modifiers and as prenominal modifiers, may be relevant in this context. Recall that postnominal ondergronds/binnensmonds
} 
unexpectedly, the structural configurations in which $-s$ externalizes the categorizer $a$ are similar to those in which $-s$ externalizes the categorizer $n$.

Let me give, right at the start of this section, the various adjectival patterns that will be examined:
a. Jan gedroeg zich anders dan Piet. Jan behaved REFL other-s than Piet 'Jan behaved differently from/than Piet.'
b. Da's nietes!
that-is not- $e-s$
'That's not true!'
c. Jan liep blootshoofds de tuin in.
Jan walked bare-s-head-s the garden in
'Jan walked into the garden bare headed.'

Before discussing each of these patterns, I start with the observation that adverbial $-s$ is blocked in contexts like (78), where the adjective (zacht) functions as a manner adverbial.

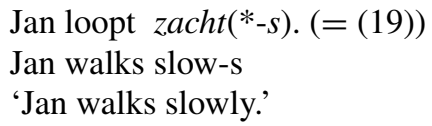

Similarly to what was observed earlier for nouns (see (15a)), the categorizing head does not surface when the adjective is "created" (derived) by head-moving the overt (free) root to the categorizing head $a$, which I take to be an affixal element. In line with what I have proposed for Root $+n$ amalgams (see Sect. 3), I assume that, in $\left[\right.$ Root $_{\text {Free }}+\mathrm{a}$ ] amalgams, affixal $a$ is adjoined to the raised root (see Chomsky 2015:12). With affixal $a$ being embedded in the complex root, $a$ is invisible from the outside. In this head-head configuration, $a$ does not surface (i.e., externalize) as $-s$.

The appearance of adverbial $-s$ is blocked not only on positive forms such as zacht in (79) but also on comparative and superlative forms: ${ }^{61}$

\section{Jan loopt zachter $\left(*_{-s}\right)$ dan Piet / het zachtst $\left(*^{*}\right)$ \\ Jan walks slower-s than Piet / the slowest-s \\ 'Jan walks slower than Piet /the slowest.'}

Following Corver (1997), I assume that comparative adjectives such as zachter are derived as follows: First, the root zacht raises to the categorizer $a$, yielding the amalgam $[\sqrt{ }$ zacht $+a]$; see (81a). This amalgam subsequently raises to a higher $[+$ comparative] functional head $(\mathrm{Q})$, as in $(81 b)$.

$$
\begin{array}{ll}
\text { a. } & {\left[\mathrm{QP}-\mathrm{er}_{[+ \text {comparative }]}[\mathrm{aP}[[\sqrt{ } \sqrt{ } \text { zacht }+\mathrm{a}][\sqrt{ } \text { zacht }]]]\right]} \\
\text { b. } & {\left[\mathrm{QP}\left[[\sqrt{ } \text { zacht }+\mathbf{a}]+-\mathrm{er}_{[+ \text {comparative }]}\right][\mathrm{aP}[[\sqrt{ } \sqrt{ } \text { zacht }+\mathrm{a}][\sqrt{ } \text { zacht }]]]\right]}
\end{array}
$$

was analyzed as a PP containing an nP, whereas prenominal ondergronds/binnensmonds was analyzed as an attributive (relational) aP to which $\mathrm{P}(\mathrm{P})$ was attached as spatial modifier.

${ }^{61}$ Adverbial $-s$ cannot appear either in between the root and the comparative morpheme: *zacht-s-er. 
In both representations, affixal $a$ is adjoined to the raised root. With affixal $a$ being embedded in the complex root, $a$ is invisible from the outside. Therefore, $a$ does not surface (i.e., externalize) as $-s$.

Although adverbial $-s$ is typically not found on comparative forms such as zachter, there is a comparative form, however, that features adverbial $-s$, namely the manneradverbial form anders (other-s, 'differently'). Before giving a structural analysis of this form, I will make some basic observations about this pattern. First of all, anders exhibits properties of a comparative construction: it includes the bound comparative morpheme $-(d) e r$ (an-der-s) and it can co-occur with the comparative dan-phrase ('than'), as in (82): 62

Jan gedroeg zich [anders dan Piet].

Jan behaved REFL other-s than Piet

'Jan behaved differently from/than Piet.'

Secondly, $-s$ is obligatorily present on anders. Thus, the $-s$-less form ander is excluded in (82). Notice that, in this respect, anders behaves differently from other comparative adjectival expressions featuring - er (see (80)). Importantly, the $-s$ of anders is not an intrinsic part of the adverbial expression. Note, for example, that in its attributive use, as in (83), it must have the -s-less form ander.

$$
\begin{aligned}
& \text { Jan vertoonde }\left[\operatorname{ander}\left(*^{*} s\right) \operatorname{gedrag}_{[\text {neuter }]}\right] \quad \text { (attributive use) } \\
& \text { Jan exhibited other }(s) \quad \text { behavior } \\
& \text { 'Jan displayed a different behavior.' }
\end{aligned}
$$

Thirdly, as we saw earlier, anders is a comparative adjective: it licenses a dan-phrase. At the same time, anders can be modified by degree modifiers that are normally found only with positive degree adjectives. This is illustrated in (84a,b). As shown by (84c), comparative forms that are formed by a synthetic comparative formation rule do not permit modification by heel erg 'very much.'
a. Jan loopt [heel erg hard].
Jan walks so very fast
'Jan walks very fast.'
b. Jan loopt [heel erg anders dan Piet].
Jan walks so very different-s than Piet
'Jan walks so differently from Piet.'
c. *Jan loopt [heel erg harder dan Piet].
Jan walks so very faster than Piet

From the above data, it can be concluded that anders has a comparative meaning but does not display the full set of properties that we find with comparative adjectives that have a rule-based syntactic derivation, as in (81) above.

\footnotetext{
${ }^{62}$ The element -der is an allomorph of -er. In Standard Dutch, -der is used after adjectives ending in $/ \mathrm{r} /$, as in ver-der 'farther'). In certain dialects, it is also used after $/ \mathrm{n} /$, as in dun-der 'thinner' (Standard Dutch: dunner). That anders contains the sequence -der in Standard Dutch suggests that it is a non-composite expression.
} 
I propose that ander $(s)$ is an adjectival expression whose comparative meaning is lexically specified. More specifically, I assume that -er is a "low" comparative derivational morpheme that heads the projection LexP, which is located in between the root-the bound morpheme $\sqrt{ }$ an-and the categorial projection aP: ${ }^{63}$

$$
\text { [aP a }[\text { LexP Lex }(=- \text { er })[\sqrt{ } \text {-an }]]]
$$

Importantly, the comparative form ander does not have a corresponding positive $(* a n)$ or superlative form (*het an-st). ${ }^{64}$ This shows that anders is not a comparative form characterized by full productivity, and that it differs in this respect from a comparative form like zachter (80), which does have a corresponding positive (79) and superlative form (80). ${ }^{65}$

The form anders is derived by raising the root to the "low" comparative morpheme, yielding the amalgam $[[\sqrt{ } a n]-(d) e r] .{ }^{66}$ Both components are bound forms: that is, they cannot occur on their own. I assume that, given the bound status of its components, the amalgam $a n+d e r$ also has a bound status. As was pointed out above, ander cannot occur on its own in a sentence like (82); $-s$-Support is required. ${ }^{67}$ Raising of the amalgam $[[\sqrt{ } a n]-(d) e r]$ to the categorizing head $a$ yields the complex head $[[[\sqrt{ } a n(d)]-e r]+a(=-s)]$. With both ander and $a$ being affixal, we end up with an exocentric head-head configuration, the subparts of which share the property of being bound-morphemic. I propose that in a configuration like this, the two heads must externalize conjointly at PF. For $a$ this means that it spells out as $-s$, a last resort operation.

$$
\begin{aligned}
& \text { a. } \quad\left[\mathrm{aP} \text { a }\left[\operatorname{LexP}[[\sqrt{ } \mathbf{a n}(\mathbf{d})]-\mathrm{er}]\left(\mathfrak{V}^{\mathrm{an}}\right]\right]\right] \\
& \text { b. } \quad\left[{ }_{a P}[[\operatorname{Lex}[\sqrt{ } \mathbf{a n}(\mathbf{d})]-e r]+a(=-s)][\operatorname{LexP}[[\sqrt{ } \text { an(d) }]-e r][\sqrt{ } \text { an }]]\right.
\end{aligned}
$$

Let me briefly return to the properties exemplified in (82) and (84). I take the comparative meaning of anders to be defined within LexP, with -er being a derivational morpheme encoding comparison, and the dan-phrase (82) occupying [Spec,LexP], as in (87). The word order anders dan Piet results from the head movement steps depicted in (87).

$$
\left[\mathrm{aP}[[\operatorname{Lex}[\sqrt{ } \mathrm{an}(\mathrm{d})]-\mathrm{er}]+\mathrm{a}(=-s)]\left[\text { LexP }[\text { dan Piet }] €_{\text {Lex }}[\sqrt{ } \text { an }(\mathrm{d})]-\mathrm{er}\right][\sqrt{ } \mathrm{an}]\right]
$$

Since anders encodes comparison as a lexical property (within LexP), and not as a syntactic property, it can be input for the formation of "degrees of comparison" at the

\footnotetext{
${ }^{63}$ The distinction between "high" -er and "low" - er parallels the distinction between the "high" classifier ' $n$ (= indefinite article) and the "low" classifier - en — both pronounced as /on/—, which was discussed in Sect. 4.2. See also De Belder et al.'s distinction between "high" diminutives and "low diminutives." I'll leave a systematic investigation of such minimal pairs for future research.

${ }^{64}$ We see the same in English: *oth, other, ${ }^{*}$ the othst.

${ }^{65}$ Another example of a comparative form featuring a "low" comparative morpheme followed by adverbial $-s$ is the locative adverb elders ('elsewhere'), which has the comparative interpretation 'in/at/to some other place.' Just like anders, elders has neither a positive form $\left({ }^{*}-e l\right)$ nor a superlative form (*el-st).

${ }^{66} \mathrm{I}$ 'll assume that /d/ in ander is an epenthetic consonant.

${ }^{67}$ I'll leave the obligatory absence of $-s$ in attributive contexts for future research; see (83). Possibly, it relates to the presence of inflectional morphology ( $-e$ or zero-inflection) on Dutch attributive adjectives.
} 
syntactic level. This explains why patterns such as (84b) are possible, in which heel erg, a phrasal modifier that typically combines with a positive adjective (84a), cooccurs with anders. Notice also that comparative meaning and superlative meaning can be expressed syntactically in combination with the adjective anders:

a. Jan gedroeg zich minder anders dan ik had gedacht.

Jan behaved REFL less other-s than I had expected

'Jan behaved less differently than I had expected.'

b. Voor Linux-gebruikers voelt dit programma het minst anders aan. for Linux-users feels this program the least other-s PRT 'For Linux-users this program will feel the least different.'

As depicted in (89), I assume that heel erg, minder and het minst are phrasal expressions occupying [Spec, QP]:

\section{[QP [heel erg/ minder/ het minst] [Q' Q [aP anders]]]}

So far, it has been shown that so-called 'adverbial $-s$ ' surfaces in a structural configuration that contains a (sub-aP) projection LexP that is headed by a bound morpheme (in casu: -er). Notice that this configuration is similar to the one assigned to nominal expressions featuring the sequence -en-s, such as namens 'on behalf of' (Sect. 4.2) and binnensmonds (b-in-en-s-mouth-s, 'inarticulately'; Sect. 4.3.2). In those expressions, -en was analyzed as the head of LexP.

I will now turn to the second adjectival pattern featuring adverbial $-s .{ }^{68}$ This pattern has the characteristic feature that the root is silent. ${ }^{69}$ I start my discussion of this construction with the mini-dialogue in (90):

(90) Person A: Jan houdt van spruitjes. Jan loves PREP Brussels-sprouts
a. Person B: Da's niet waar! a'. Da's nietes! that-is not true that-is not-e-s 'That's not true!' 'That's not true! / No, he doesn't!'
b.

Niet waar!
not true
'That's not true!'
$\mathrm{b}^{\prime}$. Nietes! not- $e-s$
'That's not true! / No, he doesn't!'

\footnotetext{
${ }^{68}$ For an alternative analysis of the patterns nietes and welles, see van Craenenbroeck (2004:Chap. 13).

${ }^{69}$ Another ellipsis-like context in which $a$ possibly surfaces as $-s$ comes from certain Dutch dialects (spoken in Flanders) in which the wh-word (h)oe 'how' is followed by $-s$, as in (ia) from Aarschot Dutch (Pauwels 1958:392). Interestingly, $-s$ does not surface when $o e$ is followed by an overt adjective, as in (ib). In future research, I hope to examine these patterns in a more in-depth way.
}

(i) a. $O e^{*}(-s)$ doe-de gij datte? (Aarschot Dutch) how(-s) do-CL you that 'How do you do that?'

b. Oe(*-s) groot is uw zoontje al? how(-s) tall is your son-DIM already 'How tall is your little son?' 
(90) represents a discussion between person A and person B. Person A claims that Jan loves Brussels sprouts, and Person B contradicts A's statement. In (90a), this is done by means of a copular construction consisting of the elements (i) da's, a contraction of the demonstrative pronoun (dat) and the copular verb (is), (ii) the negative adverb niet 'not', and (iii) the adjective waar. In (90a'), Person B's answer also corresponds to a copular construction, but now the negative adverb niet is followed by the small element - es. In (90b, b'), finally, Person B's answer is a fragment answer. In (90b), the fragment answer consists of the negative word niet and the adjective waar, while, in $\left(90 b^{\prime}\right)$, it consists of niet and -es.

Before discussing the nature of -es in $\left(90 a^{\prime}, b^{\prime}\right)$, I should point out that we find the same patterns with the affirmative adverb wel. For example, in return to Person B's negative reply in (88), Person A could react in one of the following ways:
a. Person B: Da's wel waar!
that-is AFFIRM true
a'. Da's welles!
'It is true! / Yes, it is (true)!' that-is AFFIRM- $e-s$
Wel waar! 'It is true! / Yes, it is (true)!'
b.
AFFIRM true
$\mathrm{b}^{\prime}$. Welles!
'It is true! / Yes it is (true)!' AFFIRM- $e-s$
'It is true! / Yes, it is (true)!'

I take negative niet in (90) and affirmative wel in (91) to be constituent negations. Arguments in support of this are the following: Firstly, fragment answers such as $\left(90 \mathrm{~b}, \mathrm{~b}^{\prime}\right)$ and $\left(91 \mathrm{~b}, \mathrm{~b}^{\prime}\right)$ are, generally, taken to be the result of movement of a phrase into [Spec,CP] with concomitant ellipsis of IP (see Merchant 2004; Temmerman 2013). In (90b, $\left.\mathrm{b}^{\prime}\right)$, niet waar/nietes is the fronted phrase, and in $\left(91 \mathrm{~b}, \mathrm{~b}^{\prime}\right)$, wel waar/welles is the fronted phrase. Secondly, constituent negation often involves a contrast, as in Jan heeft [niet met Marie] maar [wel met Els] gedanst (Jan has not with Mary but AFFIRM with Els danced, 'Jan danced not with Mary but (for sure) with Els'). Expressions such as welles and nietes are also typically used in contrastive contexts. Finally, and related to the previous point, welles and nietes, just like wel waar and niet waar can be conjuncts in a disjunctive coordination:
a. Jan sloot af met de vraag: "Is dit welles of nietes?"
Jan closed off with the question is this AFFIRM-es or not-es 'Jan finished with the question: "Is this true/the case or not true/the case?",

b. Jan sloot af met de vraag: "Is dit wel waar of niet waar?"

Having given some support for an analysis in which niet (90) and wel (91) are modifiers of a phrasal constituent, I will now turn to an analysis of the patterns nietes and welles. I tentatively propose that they have the structure in (93):

$$
\text { [XAP niet/wel } \left.\left[\mathrm{aP}[\sqrt{ }-e]_{\mathrm{i}}+\mathrm{a}(=-s)\left[\mathrm{t}_{\mathrm{i}}\right]\right]\right]
$$

According to this analysis, niet and wel modify aP. The sequence -es represents aP. I propose that it instantiates the pronominalization strategy of ellipsis (Corver and van Koppen 2011). Specifically, I take $-e$ (pronounced as /ə/) to be a meaningless sound 
that fills the root position, possibly for reasons of emphasis. ${ }^{70}$ As indicated, the root raises to $a$, yielding the complex head $\left[[\sqrt{ }-e]_{i}+a\right]$. So we end up with an exocentric head-head configuration, whose subparts share the property of being bound elements. In a configuration like this, the two heads must externalize conjointly at PF. As a result of their mutual dependence-both being bound elements- the two heads must materialize together, yielding a single lexical unit at the surface. I take externalization of $a$ as $-s$ to be a last resort operation: $-s$-Support must take place in order to externalize the exocentric complex head. ${ }^{71}$

I will now turn to the third adjectival pattern featuring adverbial $-s$, namely the one in $(78 \mathrm{c})$, repeated here as $(94)$ :

Jan liep blootshoofds de tuin in.

Jan walked bare-s-head-s the garden in

'Jan walked into the garden bare headed.'

Traditionally, the (somewhat archaic) pattern blootshoofds is characterized as an absolute genitival construction (Royen 1947-1954; Corver 2007). Other instances of this pattern are the following: goedsmoeds (good-s-heart/soul-s 'cheerfully'), blootsbeens (bare-s-leg-s 'with bare legs'), and blootsvoets (bare-s-foot-s 'barefoot'). Notice that these examples display two instances of so-called adverbial $-s$ : one at the end of the expression and one interspersed between the adjective and the noun: blootshoofds. From a surface perspective, the pattern looks quite similar to binnensmonds (in-sides-mouth-s 'inarticulately'), which was analyzed as a prepositional structure in which $\mathrm{P}$ (i.e., be-) selects a Construct-State-like possessive noun phrase (see (57)). In what follows, I will develop a similar type of analysis for the pattern blootshoofds in (94), which I take to be an instance of an adjectival Construct State pattern. ${ }^{72}$

I start with the observation that the absolute genitival construction in (94) has a certain resemblance to the absolute met ('with') construction (van Riemsdijk 1978):

Jan liep [met het hoofd bloot] de tuin in.

Jan walked with the head bare the garden into

'Jan walked into the garden bare headed.'

\footnotetext{
${ }^{70}$ Insertion of schwa is quite common in emphatic forms. See, for example, $i k$ 'I' versus $i k k e$ (I- $e$ 'I' (emphatic)), dat 'that' versus datte (that-e 'that' (emphatic)).

${ }^{71}$ The sequence -es is possibly also found in interjective expressions such as hebbes! (have-es 'Gotcha!'), jakkes! (yuk-es 'Yuk!'). I tentatively propose that -es in these examples represents a small nP, with -e (schwa) as a minimal spell-out of the root and $-s$ as a realization of $n$. For example, hebbes equals heb $(=$ (I) have $))+\left[n P \sqrt{ }-e_{i}+n(=-s)\left[t_{i}\right]\right]$. The $\mathrm{nP}$-es in hebbes possibly stands for the object (e.g., an insect or ball) that the speaker caught. The $\mathrm{nP}-e s$, as in jakkes, possibly, refers to the object that is evaluated (expressively) by jak.

${ }^{72}$ See Hazout (2000) and Siloni (2002) for discussion of adjectival Construct States (CS) in Modern Hebrew. An example, drawn from Siloni (2002), is given in (i):

$$
\begin{aligned}
& \text { yalda yefat mar'e } \\
& \text { girl.FSG beautiful.FSG look.MSG } \\
& \text { 'a beautiful looking girl' }
\end{aligned}
$$
}

As noted by Siloni (2002), this adjectival CS is limited to inalienable nouns (e.g., mar'e), and is typically (but not exclusively) found with body parts. Notice the parallel with the Dutch pattern blootshoofds in (94), where hoofd (head) is the inalienable possessum noun that belongs to Jan, the subject of the clause. 
The two absolute constructions have a similar interpretation. They both mean: 'with the head (being) bare.' Thus, an adjective (bloot) is predicated over an External Argument ((het) hoofd). Besides this similarity of meaning, there are also a number of striking differences between the two constructions. First of all, there is a difference in word order: The absolute met construction displays a straight order (EA + predicate), whereas the genitival absolute construction exhibits an inverted order (predicate + EA). Secondly, the absolute met construction starts with an overt P (met), whereas the absolute genitival construction lacks an overt P. Finally, the two constructions differ from each other as regards the amount of structure that can be added to the adjective (bloot) and the noun (hoofd). In the absolute genitival construction, bloot and hoofd must be absolutely bare. For example, no degree word (96a) or comparative morphology (96b) can be added to bloot, nor is it possible to have a determiner preceding the noun $(96 \mathrm{c}){ }^{73}$

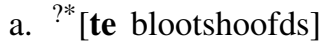 too bare-s-head-s intended meaning: 'with the head too bare'
b. *blotershoofds bare-COMPAR-s-head-s intended meaning: 'with a more bare head'
c. *bloots [het hoofds] bare-s the head-s 'intended meaning: 'with the head bare'

In the absolute met construction, both bloot and hoofd can be modified or specified, as, for example, in met het hoofd nog bloter (with the head even barer 'with the head even more bare'), and met het hoofd iets te bloot (with the head somewhat too bare 'with the head a little too bare').

In view of the similarity of meaning - that is, both constructions encode a predication relationship between a predicate (bloot) and an EA ((het) hoofd) - I propose that the two absolute constructions start out from the same underlying configuration, namely a small clause structure. I assume this structure consists of a functional head (Pred) that mediates between the predicate (the complement of PredP) and the EA (the specifier of PredP); see Bowers 1993; Den Dikken 2006. Example (97a) represents the absolute met construction in (95), and (97b) the absolute genitival construction in (94).

$$
\text { a. [PP Spec [P' met [PredP [DP het hoofd] [Pred'Pred [DegP (te) bloot]]]]] }
$$

\footnotetext{
${ }^{73}$ In Modern Hebrew, only simplex adjectives - that is, adjectives that are not formed by an adjectival formative (suffix) — can occur in adjectival constructs (Siloni 2002). Example (i), drawn from Siloni (2002), presents a minimal pair: the simplex form ge' $e$ ('proud') allows a construct, but the suffixed form ga'avtan ('proud') does not.
}

(i)
a. ge'e levav proud heart
b. *ga'avt-an levav proud-suffix heart 
b. $\quad\left[\mathrm{PP} \operatorname{Spec}\left[\mathrm{P}, \mathrm{P}_{\varnothing}[\operatorname{PredP}[\mathrm{nP} \mathrm{n}(=-\mathrm{s})[\sqrt{ }\right.\right.$ hoofd $]][$ Pred' Pred $[\mathrm{aP}$ a $(=-\mathrm{s})$ $[\sqrt{ }$ bloot $]]]]]$

I assume that the inverted word order (Pred + EA) results from movement of aP to $[\mathrm{Spec}, \mathrm{PP}] .{ }^{74}$ Both the EA (nP) and the predicate $(\mathrm{aP})$ are minimal phrasal projections, in the sense that they consist solely of a categorizing head and a Root-complement. In each projection, the root moves to the categorial head, creating the complex head $[$ root $+n / a]$. I propose that $-s$-Support is needed because $\sqrt{ }$ hoofd and $\sqrt{ }$ bloot are bound roots. When the bound root raises to $n / a$, we get a complex head whose com-

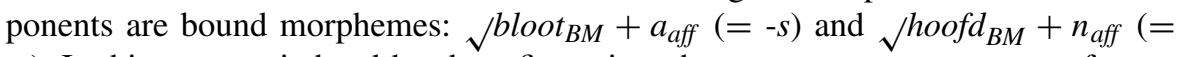
$-s$ ). In this exocentric head-head configuration, the two components must surface at PF. Because of their mutual dependence, the two elements must materialize together, yielding a single lexical unit at the surface: bloots and hoofds.

Summarizing, I have tried to show in this section that $-s$-Support also applies to the categorizing node $a$. On the basis of three case studies, it was shown that $-s$-Support in the adjectival domain is attested in the same types of structural configurations as $-s$-Support in the nominal domain. In short, the phenomenon of adverbial $-s$ (reinterpreted here as $-s$-Support) is another illustration of the existence of cross-categorial symmetry. ${ }^{75}$

\section{Conclusion}

This article examined the grammatical nature and distributional behavior of socalled adverbial $-s$ in Dutch, a phenomenon that, to my knowledge, has received no or very little attention in modern theoretical linguistics. As for the grammatical nature of $-s$, I proposed that adverbial $-s$ is a last resort affixal manifestation of the categorizing nodes $n$ and $a$. On the basis of a large variety of adverbial expressions, I showed that $-s$-Support occurs in a restricted number of complex-headconfigurations, specifically: (i) $\left[\operatorname{Root}_{\text {Silent }}+n / a(=-s)\right]$, (ii) $\left[\operatorname{Root}_{\text {Bound }}+n / a(=-s)\right]$, and (iii) $[[$ Root $+L e x]+n / a(=-s)]$. An important outcome of this study is that many linguistic expressions, traditionally identified as adverbs, are syntactic objects with an inner structure having $\mathrm{nP} / \mathrm{aP}$ as a subcomponent. If my reinterpretation of adverbial $-s$ as being an affixal realization of the categorizing nodes $n$ and $a$ is on the right track, it can be used as a diagnostic element for identifying other pieces of nominal/adjectival structure in the build of Dutch. Just for the sake of illustration, I have given in (98) a list of other "adverbs" featuring adverbial -s. Clearly, the phenomenon is quite common in Dutch and opens ways for further investigation.

deels (part-s 'partly'), daags (na Kerstmis) (day-s (after Christmas) 'one day (after Christmas)'), meermaals (more-time-s 'several times / repeatedly'), slechts ('merely/just'), steeds ('constantly / time and again'), reeds

\footnotetext{
${ }^{74}$ Note that the displacement of the aP bloots to [Spec,PP] is quite similar to the displacement of namens (name-en-s, 'on behalf of') to [Spec,PP], which was discussed in Sect. 4.2.

${ }^{75}$ The quest for cross-categorial symmetry has played an important role throughout the history of generative grammar. See, for example, Chomsky (1970), Stowell (1982), Abney (1987), and Szabolcsi (1987).
} 
(ready-s 'already'), onverwachts (unexpected(-s) unexpectedly'), veels (te duur) (colloquial: much-s (too expensive) 'much (too expensive)'), niet als te groot (colloquial: not all-s too tall 'not very tall'), dikwijls (thick-time$\mathrm{s}$ 'often') ruimschoots (ample sheet-s (sailing) 'amply'), enigszins (somes-way-s 'somewhat/slightly'), geenszins (no-s-way-s 'by no means/not at all'), alleszins (all-s-way-s 'in all respects'), zelfs (self-s 'even'), (al)dus ((all)the/that-s 'hence/thus'), gemakshalve (convenience-s-half 'for convenience'), links (left-s 'on the left side'), rechts (right-s 'on the right side'), stapsgewijs (step-s-wise 'stepwise/gradually'), ergens (somewhere-s 'somewhere'), hoogstens (high-SUPERLATIVE-en-s 'at most', telkens (at-each-en$\mathrm{s}$ 'each/every time'), overigens (other-en-s 'besides/by the way'). ${ }^{76}$

One may wonder whether $-s$ as a manifestation of the categorial node $n / a$ is still a productive phenomenon in present-day Dutch. That is, could it be that these expressions ending in $-s$ are unanalyzable units, and that $-s$-Support is not, or no longer, a rule that is active in a Dutch speaker's grammar (I-language)? On the basis of grammarbehavioral restrictions of various adverbial expressions, I have tried to show that these expressions do have an internal syntactic organization, with $n / a$-externalized as $-s$ at the sound surface-as a core component. The productivity of $-s$-Support is possibly supported by a number of other phenomena that deserve further investigation. Firstly, there is the appearance of $-s$ in shortened proper names and kinship terms, as in Babs (from Barbara), Mams (Mom-s, 'Mommy'), and Paps (Pop-s, 'Daddy'). This shortening - a sort of ellipsis within the root-induces the appearance of $-s$. Possibly, these $-s$-bearing names/kinship terms are not DPs but small nPs, with the proper name/kinship term being a bound root in need of "support", as in $\left[n P \sqrt{ } B a b_{i}+\mathrm{n}(=-s)\right.$ $\left.\left[t_{i}\right]\right] .{ }^{77}$ Secondly, there is the productive use of $-s$ after greeting expressions such as tot \{bels/ziens/hoors/spreeks/schrijfs/e-mails/skypes/whats-apps!\} (till call-s/see-s/hears/talk-s/write-s/e-mail-s/skype-s/whatsapps). The element $-s$ expresses the nouniness of the complement of the preposition tot, as in $\left[P P\right.$ tot $\left.\left[{ }_{n P} \sqrt{ } b e l_{i}+\mathrm{n}(=-s)\left[t_{i}\right]\right]\right]$. Thirdly and more speculatively, certain interjections in Dutch end with $-s$, such as Oeps! ('Oops!'), Hups! (Hop-s 'away we go!'), Floeps! (flop-s 'away we go!'), Bliksems! (lightning-s 'dammit!'). Possibly, there is a hidden nominal element in these interjections, which would mean that even interjections belong to the domain of syntax, in the sense of having an inner structure (see also fn. 71).

The aim of this article was to give an in-depth analysis of the grammar of adverbial $-s$ in Dutch. From a broader theoretical perspective, it aimed to contribute to answer-

\footnotetext{
${ }^{76}$ Notice that the adverbs ergens, hoogstens, telkens and overigens have the sequence en-s at the end. Possibly, the component en attested here is the same element as the one attested in the expressions namens, binnensmonds and vliegensvlug; that is, en is the head of a LexP hierarchically located in between the root and $\overline{\mathrm{nP}}$. For example: [PP te [QP elk $\left.{ }_{n} P(n)-s\right)[$ LexP $\left.\left.\left.-e n[\sqrt{ } T I M E]]\right]\right]\right]$.

${ }^{77}$ I leave the question about the nature of Dutch possessive $-s$ for future research. Interestingly, possessive -s typically occurs with "simplex" possessor-nouns, as in Jans fiets (Jan's bike) and vaders fiets (father's bike), and not with complex possessors: *de leraars fiets (the teacher's bike). Possibly, these possessors are small nPs (rather than DPs), whose categorial head $n$ surfaces as $-s$. Present-day Dutch possessivepronominal forms such as wiens (whose) and diens (that one's/that person's) possibly feature the classifying (i.e., individuating) Lex-head. Schematically: [DP wie $[n P-s[\operatorname{LexP}-n[\sqrt{ } P E R S O N]]]$, where wiens is derived by two movement steps: (i) Root to Lex, and (ii) [Root+Lex] to $n$.
} 
ing the question about the existence of adverbs as a separate syntactic category; that is, do adverbs constitute a separate syntactic category (i.e., a lexical category) within the parts of speech (i.e., besides nouns, verbs, adjectives and (certain) adpositions) or can they be reduced to other syntactic categories? I hope to have shown on the basis of this case study on Dutch adverbial $-s$ that it is worth trying to reduce so-called adverbs to other syntactic categories. For this reduction strategy we need to detect the inner structure of adverbs, including the linguistic atoms that hint at the presence of a particular type of structure. In this article we used the element $-s$ as a sign for detecting nominal or adjectival structure within linguistic expressions that are traditionally categorized as adverbs. The question obviously arises to what extent this reductionist approach can be extended to other types of adverbs. For reasons of space, I confine myself to a single illustration: the quantifier (Q) al 'all.' This grammatical formative typically surfaces in nominal structures, as in al het water 'all the water,' and thus may be used as a means for detecting nominal structure within "adverbs." Some illustrations of Dutch adverbs featuring al are given in (99). I will leave an in-depth analysis of these patterns for future research.

altijd (all-time 'always'), aldus (all-thus 'thus/in that way'), aldaar (all-there 'there/at that place'), alvast (all-ready 'already'), alreeds (all-ready-s 'already'), alom (all-about 'everywhere'), aldoor (all-through 'all the time'), meestal (most-all 'mostly'), veelal (much-all 'often'), overal (over-all 'everywhere'), nogal (yet-all 'rather/somewhat')

Another issue that I leave for future research is the question as to whether equivalents of adverbial $-s$ can be found in other languages. ${ }^{78}$ Recall from Sect. 3 that adverbial $-s$ relates to genitival case, which, in line with Emonds (1985) and Pesetsky (2013), I interpreted as an affixal noun, and more specifically as affixal $n$. Also here I confine myself to giving some illustrations of "adverbs" featuring an element that one might possibly want to analyze as a realization of the categorizing node $n$. My examples come from French and the pertinent element is the meaningless element $d e$ 'of,' which has been analyzed as a manifestation of genitival case. If 'genitival case' is affixal $n$, one might interpret the element $d e$ in the following French adverbs as a sign of the presence of nominal structure, that is: $\left[{ }_{n P} n(=\mathrm{de})+\right.$ Root $] .{ }^{79}$ Again, I leave an in-depth analysis of these patterns for future research.

(100) de même (of same 'likewise'), tout de même (all of same 'anyway/nevertheless'), tout $d$ 'abord (all of access 'first of all'), tout de suite (all of continuation 'immediately/straight away'), dehors (of-out 'outside/outdoors'), dedans (off-inside/indoors), (partir) de nuit ((to leave) of night '(to leave) at night), davantage (of+advantage 'more'), debout (of+end/tip 'up/upright'), de nouveau (of+new 'again')

Let me, finally, point out that a better understanding of the inner organization of socalled adverbs may give us more insight into the way they are integrated into larger

\footnotetext{
${ }^{78}$ See fn. 1 for examples of adverbs featuring adverbial $-s$ in other Germanic languages.

${ }^{79}$ See also Pesetsky (2013:98-102) for the idea that French $d e$ is a manifestation of affixal N/n.
} 
syntactic structures. ${ }^{80}$ If one follows Cinque (1999) in assuming that "adverbs" occupy the specifier positions of designated functional heads, one might expect there to be interactions (e.g. feature matching) between properties associated with the composite "adverb" and (properties of) the functional head in the clausal spine.

In conclusion, adverbial $-s$ is a fascinating phenomenon, which is widespread but somewhat hidden in the build of Dutch. Its appearance is not arbitrary and unpredictable, but, rather, restricted and predictable. I hope to have shown that adverbial $-s$ provides further support for the idea that categorizing heads are part of human language, and that so-called adverbs can be reduced to other parts of speech. Importantly, my investigation of adverbial $-s$ has also shown that phenomena such as silent nouns and the construct state pattern are important elements of Dutch morphosyntax.

Acknowledgements I would like to thank three anonymous $N L L T$ reviewers for their constructive comments and suggestions. This article has also benefited from comments by the participants of my Comparative Syntax class at the University of Connecticut during the spring term of the academic year 2018-2019. Parts of this article were presented at Utrecht University (2014), University of Paris 8 (2015), Georgetown University, Washington D.C. (2017), Leiden university (2017), Annesso Cartesiano, Villa Salmi, Stoppe d'Arca/Arezzo (2017), Queen Mary, University of London (2018), ZAS Berlin (2018). I would like to thank the audiences for their questions and comments.

\section{Declarations}

Conflict of Interest The author declares no conflict of interest.

Open Access This article is licensed under a Creative Commons Attribution 4.0 International License, which permits use, sharing, adaptation, distribution and reproduction in any medium or format, as long as you give appropriate credit to the original author(s) and the source, provide a link to the Creative Commons licence, and indicate if changes were made. The images or other third party material in this article are included in the article's Creative Commons licence, unless indicated otherwise in a credit line to the material. If material is not included in the article's Creative Commons licence and your intended use is not permitted by statutory regulation or exceeds the permitted use, you will need to obtain permission directly from the copyright holder. To view a copy of this licence, visit http://creativecommons.org/licenses/by/ $4.0 \%$.

\section{References}

Abney, Steven. 1987. The English noun phrase in its sentential aspect. PhD Dissertation, MIT.

Aboh, Enoch. 2010. The P route. In Mapping spatial PPs: The cartography of syntactic structures, eds. Guglielmo Cinque and Luigi Rizzi. Vol. 6, 225-260. Oxford: Oxford University Press.

Alexiadou, Artemis. 2013. Adverbial and adjectival modification. In The Cambridge handbook of generative syntax, ed. Marcel den Dikken, 458-484. Cambridge: Cambridge University Press.

Baker, Mark C. 2003. Lexical categories: Verbs, nouns, and adjectives. Cambridge: Cambridge University Press.

Borer, Hagit. 1999. Deconstructing the construct. In Beyond principles and parameters, eds. K. Johnson and I. Roberts, 43-90. Dordrecht: Kluwer.

Borer, Hagit. 2005. In name only (Structuring sense, vol. I), Oxford: Oxford University Press.

Bowers, John. 1975. Adjectives and adverbs in English. Foundations of Language 13: 529-562.

Bowers, John. 1993. The syntax of predication. Linguistic Inquiry 24: 591-656.

Bresnan, Joan, and Jane Grimshaw. 1978. The syntax of free relatives in English. Linguistic Inquiry 9(3): 331-391.

${ }^{80}$ I would like to thank a reviewer for emphasizing this point. 
Chomsky, Noam. 1970. Remarks on nominalization. In Readings in English transformational grammar, eds. Roderick A. Jacobs and Peter S. Rosenbaum, 184-221. Waltham: Ginn and Company.

Chomsky, Noam. 1981. Lectures on government and binding. Dordrecht: Foris.

Chomsky, Noam. 1986. Knowledge of language: Its nature, origin and use. New York: Praeger.

Chomsky, Noam. 1993. A Minimalist program for linguistic theory. In The view from building 20: Essays in linguistics in honor of Sylvain Bromberger, eds. Kenneth Hale and Samuel Keyser, 1-52. Cambridge: MIT Press.

Chomsky, Noam. 1995. The Minimalist program. Cambridge: The MIT Press.

Chomsky, Noam. 2001. Derivation by phase. In Ken Hale. A life in language, ed. Michael Kenstowicz, 1-52. Cambridge: MIT Press.

Chomsky, Noam. 2013. Problems of projection. Lingua 130: 33-49.

Chomsky, Noam. 2015. Problems of projection: Extensions. In Structures, strategies, and beyond: Studies in honour of Adriana Belletti, eds. Elisa Di Domenico, Cornelia Hamann, and Simona Matteini, 1-16. Amsterdam: John Benjamins.

Cinque, Guglielmo. 1993. A null theory of phrasal and compound stress. Linguistic Inquiry 24: 239-297.

Cinque, Guglielmo. 1994. On the evidence for partial N-movement in the Romance DP. In Studies in honor of Richard S. Kayne, eds. Guglielmo Cinque, Jan Koster, Jean-Yves Pollock, Luigi Rizzi, and Raffaela Zanuttini, 85-110. Washington: Georgetown University Press.

Cinque, Guglielmo. 1999. Adverbs and functional heads. A cross-linguistic perspective. Oxford: Oxford University Press.

Cinque, Guglielmo. 2005. Deriving Greenberg's universal 20 and its exceptions. Linguistic Inquiry 36: $315-332$.

Corver, Norbert. 1997. The internal syntax of the Dutch extended adjectival projection. Natural Language and Linguistic Theory 15: 289-368.

Corver, Norbert. 2007. Dutch 's-Prolepsis as a copying phenomenon. In The copy theory of movement, eds. Norbert Corver and Jairo Nunes, 175-216. Amsterdam: John Benjamins.

Corver, Norbert, and Marjo van Koppen. 2011. NP-ellipsis with adjectival remnants: a micro-comparative perspective. Natural Language and Linguistic Theory 29: 371-421.

Corver, Norbert, et al. 2011. Database Diversity in Dutch DP Design. (DDiDD). Utrecht, UiL-OTS. Available at: http://www.meertens.knaw.nl/dp_vragenlijst/, last accessed 21 September 2021.

van Craenenbroeck, Jeroen. 2004. Ellipsis in Dutch dialects. Utrecht: LOT.

De Belder, Marijke. 2011. Roots and affixes: Eliminating lexical categories from syntax. Utrecht: LOT.

De Belder, Marijke, Noam Faust, and Nicola Lampitelli. 2014. On a low and a high diminutive: Evidence from Italian and Hebrew. In The syntax of roots and the roots of syntax, eds. Artemis Alexiadou, Hagit Borer, and Florian Schäfer, 149-163. Oxford: Oxford University Press.

De Bont, A. P. 1958. Dialekt van Kempenland. Meer in het bijzonder d'Oerse taol. Deel 1. Klank-en vormleer en enige syntactische bijzonderheden. Assen: Van Gorcum \& Comp. N.V.

Déchaine, Rose-Marie, and Mireille Tremblay. 1996. Adverbial PPs and prepositional adverbs in French and English. Canadian Linguistics Association Proceedings. Calgary: University of Calgary Working Papers in Linguistics.

Delfitto, Denis, and Gaetano Fiorin. 2017. Adverb classes and adverb placement. In The Wiley-Blackwell companion to syntax, eds. Martin Everaert and Henk van Riemsdijk, 1-29. Oxford: Wiley-Blackwell.

Den Dikken, Marcel. 2006. Relators and Linkers: The syntax of predication, predicate inversion, and copulas. Cambridge: MIT Press.

Den Dikken, Marcel. 2010. On the functional structure of locative and directional PPs. In Mapping spatial PPs: The cartography of syntactic structures, eds. Guiglielmo Cinque and Luigi Rizzi. Vol. 6, 74-126. Oxford: Oxford University Press.

Embick, David, and Alec Marantz. 2008. Architecture and blocking. Linguistic inquiry 39: 1-53.

Embick, David, and Rolf Noyer. 2001. Movement operations after syntax. Linguistic inquiry 32(4): $555-595$.

Emonds, Joseph. 1976. A transformational approach to English syntax: Root, structure preserving and local transformations. New York: Academic Press.

Emonds, Joseph. 1985. A unified theory of syntactic categories. Dordrecht: Foris.

Emonds, Joseph. 1987a. Parts of speech in generative grammar. Linguistic Analysis 17: 3-43.

Emonds, Joseph. 1987b. The invisible category principle. Linguistic Inquiry 18(4): 613-632.

Harley, Heidi, and Rolf Noyer. 1999. State of the art article: Distributed morphology. GLOT International 4: 3-9.

Fábregas, Antonio, and Rafael Marín. 2017. Problems and questions in derived adjectives. Word Structure 10.1: 1-26. 
Hazout, Ilan. 2000. Adjectival genitive constructions in Modern Hebrew. The Linguistic Review 17: $29-52$.

Hoekstra, Teun. 1988. Small clause results. Lingua 74: 101-139.

Jackendoff, Ray. 1972. Semantic interpretation in generative grammar. Cambridge: MIT Press.

Jackendoff, Ray. 1996. The architecture of the linguistic-spatial interface. In Language and space, eds. Paul Bloom, Mary A. Peterson, Lynn Nadel, and Merrill F. Garrett, 1-30. Cambridge: MIT Press.

Kayne, Richard S. 2003. Silent years, silent hours. In Grammar in focus: Festschrift for Christer Platzack, eds. Lars-Olof Delsing, Cecilia Falk, Gunlog Josefsson, and Halldór Á. Sigurðsson. Vol. 2, 209-226. Lund: Wallin and Dalhol.

Koopman, Hilda. 2000. Prepositions, postpositions, circumpositions and particles: The structure of Dutch PPs. In The syntax of specifiers and heads, ed. Hilda Koopman, 204-260. London: Routledge.

Koster, Jan. 1975. Dutch as an SOV language. Linguistic Analysis 1: 111-136.

Larson, Richard. 1985. Bare NP-adverbs. Linguistic Inquiry 16: 595-621.

Longobardi, Giuseppe. 2001. Formal syntax, diachronic minimalism, and etymology: The history of French Chez. Linguistic Inquiry 32: 275-302.

Lowenstamm, Jean. 2014. Derivational affixes as Roots (Phasal Spell-Out meets English stress shift). In The syntax of roots and the roots of syntax, eds. Artemis Alexiadou, Hagit Borer, and Florian Schäfer, 230-259. Oxford: Oxford University Press.

Marantz, Alec. 1997. 'Cat' as a phrasal idiom: Consequences of late insertion in Distributed Morphology. Ms., MIT.

Marantz, Alec. 2000. Words. Unpublished ms., NYU.

McCawley, James. 1988. Adverbial NPs: Bare or clad in see-through garb? Language 64: 583-590.

Merchant, Jason. 2004. Fragments and ellipsis. Linguistics and Philosophy 27: 661-738.

Mitrović, Moreno, and Phoevos Panagiotidis. 2020. Adjectives exist, adjectivisers do not: A bicategorial typology. Glossa: a journal of general linguistics 5(1): 58. https://doi.org/10.5334/gjgl.940. 1-28.

Nunes, Jairo. 2004. Linearization of chains and sideward movement. Cambridge: MIT Press.

Overdiep, Gerrit. 1940. De volkstaal van Katwijk aan Zee. Antwerpen: N.V. Standaard-boekhandel.

Pauwels, J. L. 1958. Het dialect van Aarschot en omstreken. V. I. Belgisch Interuniversitair Centrum voor Neerlandistiek.

Pesetsky, David. 2013. Russian case morphology and the syntactic categories. Cambridge: MIT Press.

Pretorius, Erin. 2017. Spelling out P. A unified syntax of Afrikaans adpositions and V-particles. Utrecht: LOT.

van Riemsdijk, Henk. 1978. A case study in syntactic markedness. Dordrecht: Foris.

van Riemsdijk, Henk. 2001. A far form simple matter: Syntactic reflexes of syntax-pragmatics misalignments. In Perspectives on semantics, pragmatics, and discourse: A festschrift for Ferenc Kiefer, 21-41. Amsterdam: John Benjamins.

Ritter, Elizabeth. 1988. A head-movement approach to Construct-State noun phrases. Linguistics 26: 909-929.

Rizzi, Luigi. 1990. Relativized minimality. Cambridge: MIT Press.

Rouveret, Alain, and Jean-Roger Vergnaud. 1980. Specifying reference to the subject: French causatives and conditions on representations. Linguistic Inquiry 11: 97-202.

Royen, Gerlach. 1947-1954. Buigingsverschijnselen in het Nederlands. Delen I-IV. Amsterdam: NoordHollandsche Uitgevers Maatschappij.

Selkirk, Elisabeth. 1972. The phrase phonology of English and French. PhD dissertation, MIT. New York: Garland.

Shlonsky, Ur. 2004. The form of Semitic noun phrases. Lingua 114(12): 1465-1526.

Van der Sijs, Nicoline. (Editor). 2010. Etymologiebank, Available at: http://etymologiebank.nl/, last accessed 21 September 2021

Siloni, Tal. 1996. Hebrew noun phrases: generalized noun raising. In Parameters and functional heads, eds. Adriana Belletti and Luigi Rizzi, 239-267. New York: Oxford University Press.

Siloni, Tal. 2002. Adjectival constructs and inalienable constructions. In Themes and issues in the syntax of Arabic and Hebrew, eds. Jamal Ouhalla and Ur Shlonsky, 161-187. Dordrecht: Kluwer Academic Publisher.

Stowell, Tim. 1982. Subjects across categories. The Linguistic Review 2: 285-312.

Svenonius, Peter. 2006. The emergence of Axial Parts. Nordlyd 33: 49-77.

Szabolcsi, Anna. 1987. Functional categories in the noun phrase. In Approaches to Hungarian. Theories and analyses, ed. István Kenesei, 167-190. Szeged: JATE.

Temmerman, Tanja. 2013. The syntax of Dutch embedded fragment answers: on the PF-theory of islands and the WH/sluicing correlation. Natural Language and Linguistic Theory 31: 235-285. 
de Vooys, Gerrit. 1967. Nederlandse Spraakkunst. Groningen: Wolters.

Wiltschko, Martina. 2005. Why should diminutives count? In Organizing grammar: Linguistic studies in honor of Henk van Riemsdijk, eds., Hans Broekhuis, Norbert Corver, Riny Huijbregts, Ursula Kleinhenz, and Jan Koster, 669-678. Berlin: Mouton de Gruyter.

Wood, Jim, and Alec Marantz. 2017. The interpretation of external arguments. In The verbal domain, eds. Roberta D'Alessandro, Irene Franco, and Ángel J. Gallego, 255-278. Oxford: Oxford University Press.

Publisher's Note Springer Nature remains neutral with regard to jurisdictional claims in published maps and institutional affiliations. 